\title{
Models of Sectoral Reallocation
}

\author{
Eric Swanson \\ Board of Governors of the Federal Reserve System \\ eswanson@frb.gov
}

\begin{abstract}
This paper demonstrates several strengths and shortcomings of models of sectoral reallocation. Although these models demonstrate that sectoral reallocation can be an important amplification and propagation mechanism for exogenous shocks, they are essentially unable to explain any effects of sectoral reallocation on aggregate productivity or related quantities (such as the real wage or observations of aggregate increasing returns to scale), unless a wedge is introduced into the model that drives the marginal products of inputs in different sectors apart in steady state. In particular, costs of adjustment, lags to adjustment, and intermediate input linkages are not sufficient. This paper offers a solution to this shortcoming in the form of variable sectoral capital utilization, the marginal product of which can easily differ across sectors in steady state. Reallocations of production between sectors in this setting are then shown to have first-order effects on aggregate productivity and real wages, and can explain the procyclicality of these variables without reliance on large, exogenous, and persistent shocks to technology.
\end{abstract}

JEL Classification: E32, O47

Version 1.3.1

February 24, 1999

I thank Michael Horvath, Robert Hall, John Taylor, Pierre-Olivier Gourinchas, John Fernald, and others at Stanford and the Federal Reserve Board for valuable comments and suggestions. All errors and omissions are mine. The views expressed in this paper do not necessarily represent those of the Federal Reserve System or its Board of Governors. 


\section{Introduction}

The idea that sectoral reallocation could be an important cause or contributor to business cycles has been recognized since at least Ricardo's Principles in 1817. David Lilien's seminal paper in 1982 sparked much of the current research and debate of the issue. A permanent shift in demand or technology, so the story goes, can require a substantial shift in inputs across sectors, with the frictions associated with such a move manifesting themselves in the aggregate as a recession.

Subsequent research has largely confirmed that sectoral reallocation is an important feature of the business cycle. Davis (1987) rectifies many of the flaws in Lilien's and Abraham and Katz's (1986) original empirical work and finds that "fluctuations in the pace of labor reallocation contribute greatly to unemployment fluctuations" (p. 388). Davis and Haltiwanger (1990), using plant-level data, confirm these findings and conclude that "the frictions associated with the reallocation of jobs and workers play a major role in business cycle fluctuations. We are doubtful that a satisfactory understanding of aggregate fluctuations will emerge from theories that ignore these frictions" (p. 166). Campbell and Kuttner (1996), using a VAR framework, find that under a variety of identifying restrictions, reallocative shocks account for at least $27 \%$ of the variance in aggregate employment, and possibly much more. They conclude: "exogenous disturbances to the economy's optimal allocation of labor, reallocation shocks, account for a large fraction of employment variance" (p. 113).

Many researchers have demonstrated important roles for sectoral reallocation in equilibrium models of the business cycle as well. Long and Plosser (1983) demonstrate that even i.i.d. sectoral productivity shocks yield output fluctuations that are persistent and correlated across sectors, because the output of one sector is often fed into others as an intermediate input. Davis and Haltiwanger (1990) and Rogerson (1987) build models in which the optimal timing of labor reallocation depends significantly on the state of the aggregate economy. ${ }^{1}$ As the need for reallocation in the economy accumulates over time, a small aggregate shock can induce a large amount of labor reallocation (and hence unem-

\footnotetext{
${ }^{1}$ For example, the opportunity cost of forgone production is lower during an aggregate downturn, making labor reallocation more attractive (Davis and Haltiwanger (1990)). In Rogerson (1987), reallocation from a declining industry to a growing one is optimal during an aggregate downturn if the declining industry is more cyclically sensitive than the growing industry, and during an aggregate upturn if the declining industry is less cyclically sensitive.
} 
ployment) due to this timing effect, thereby greatly magnifying the impact of the shock. Hamilton (1986) shows that even fairly moderate movements in the price of oil can lead to large reallocations of demand and labor across sectors, and thus large movements in aggregate quantities, because oil is an important input into the production of some sectors and not others. ${ }^{2}$ Phelan and Trejos (1995) and Ramey and Shapiro (1997) demonstrate that shocks to the demand side of the economy, such as government purchases, also can be greatly magnified by their sectoral implications. This finding is significant because aggregate equilibrium business cycle models typically find only a very minor role for such shocks.

More recently, researchers have begun to look to sectoral reallocation as a potential explanator of other business cycle puzzles as well. Basu and Fernald (1997a) attribute observations of aggregate increasing returns to scale to cyclical movement in the share of production accounted for by, e.g., durables and nondurables manufacturing. If durables manufacturing is characterized by higher returns to scale and higher markups than nondurables, then a reallocation from the latter to the former results in an increase in aggregate output relative to inputs, and apparent aggregate increasing returns to scale. More recently, Basu and Fernald (1997b) have applied the same idea to observations of procyclical aggregate productivity: reallocations from a low returns-to-scale, low-markup sector to one with high returns and high markups will be partially measured as increases in the Solow residual, to the extent that they are not captured by econometric instruments for the inputs and attributed to economywide increasing returns. This implies a role for sectoral reallocation in aggregate productivity movement as well. Even the classical, constant-returns model of Phelan and Trejos (1995) is often cited as evidence that aggregate productivity is significantly influenced by sectoral reallocation. The intuition is as follows: in response to a reallocative shock in a sectoral model, the capital stock (or other fixed or quasi-fixed inputs) will be allocated suboptimally ex post, leading to a decrease in aggregate output relative to aggregate inputs, and hence a decline in overall productivity. A similar effect has been offered by Davis (1987) as a potential explanator for the procyclicality of real wages.

This paper analyzes models of sectoral reallocation and some of their limitations in

\footnotetext{
${ }^{2}$ Or, alternatively, oil is an important complement to the consumption of some sectors' output, and not others'. Either property is sufficient to generate the reallocation effects Hamilton discusses.
} 
the uses mentioned above. In particular, the ability of such models to explain aggregate increasing returns to scale, procyclical productivity, and procyclical real wages is severely limited unless a wedge is introduced into the model that drives the marginal products of inputs in different sectors apart in steady state. This criterion is satisfied by Basu and Fernald (1997a,b), but not by the other models mentioned above. Adjustment costs or adjustment lags to capital (or other inputs) are by themselves not sufficient to generate anything other than second-order movements in these aggregate quantities.

In addition, this paper will argue that variable sectoral capital utilization is a far superior framework to increasing returns and imperfect competition for generating first-order procyclical effects on aggregate productivity and real wages. One of the main advantages of this approach is that empirical support for increasing returns to scale in sectors of the U.S. economy, or in plant-level data, is very weak, while the evidence for variable capital utilization, and differences in the cyclicality of utilization across sectors, is very strong. Moreover, in contrast to the empirical, reduced-form decompositions of Basu and Fernald (1997a,b), this paper demonstrates how to model these effects within a simple, structural dynamic stochastic general equilibrium (DSGE) setting. It is thus partially a generalization of the equilibrium business cycle modeling of capital utilization presented in Burnside and Eichenbaum (1996), Greenwood, Hercowitz, and Huffman (1988), and others to multiple sectors. Finally, if durable goods manufacturing is characterized not by higher returns to scale, but instead by greater cyclicality in the utilization of capital, an increase in the fraction of production accounted for by durables manufacturing will appear in the aggregate as an increase in output relative to inputs, an increase in aggregate productivity, and an increase in real wages. This matches the empirical facts of the business cycle.

The remainder of this paper proceeds as follows. In section two, the standard onesector DSGE model is directly generalized to mutliple sectors and the effects of sectoral reallocation within the framework of the model are briefly explored. Section three demonstrates the need for a wedge between the long-run marginal products of inputs in different sectors in any model of sectoral reallocation, if significant effects of reallocation on aggregate returns to scale, productivity, and real wages are to be observed. Section four augments the model of section two to include variable capital utilization, and demonstrates how the marginal product of utilization can differ across sectors in steady state, so that reallocations of production between sectors will generally lead to first-order effects on 
the agregate variables mentioned above. Section five presents a series of simulations that verify the practical importance of these effects, and demonstrates how a sectoral reallocations model with capital utilization can greatly magnify the effects of exogenous shocks on the system. Section six notes potential generalizations of the framework and concludes.

\section{A Classical Model of Sectoral Reallocation}

\subsection{The Baseline Model}

In discussing properties of sectoral reallocations models in general, it is helpful to have a simple example of such a model in mind. I thus begin with a direct generalization of the standard one-sector DSGE model of King, Plosser, and Rebelo (1988) to multiple sectors. ${ }^{3}$ The one-sector version of this model has the basic framework:

$$
\begin{array}{rlrl}
\text { Preferences: } & U & \equiv \sum_{t=0}^{\infty} \beta^{t} \frac{C_{t}^{1-\sigma}}{1-\sigma} v\left(1-L_{t}\right) \\
\text { Production: } & Y_{t} & \equiv A_{t} F\left(K_{t}, X_{t} L_{t}\right) \\
& \equiv A_{t} K_{t}^{1-\alpha}\left(X_{t} L_{t}\right)^{\alpha} \\
\text { Capital Stock: } & K_{t+1} & =(1-\delta) K_{t}+\left(Y_{t}-C_{t}-G_{t}\right) \\
\text { Government: } & \tau Y_{t} & =G_{t}+T_{t}
\end{array}
$$

Here $C_{t}$ denotes consumption at time $t, L_{t}$ labor, $Y_{t}$ output, $K_{t}$ capital, $G_{t}$ government purchases, $\tau$ the income tax rate, $\delta$ the depreciation rate, $\beta$ the representative agent's discount factor, and $T_{t}$ the lump-sum transfer to consumers (or tax if negative). $A_{t}, X_{t}$, $P_{C t}$, and $P_{K t}$ will be explained below. For simplicity, the population is assumed to be stable and normalized to unity in every period.

Equation (I-1) is the representative agent's objective function, with total labor endowment normalized to unity. The function $v\left(1-L_{t}\right)$ is unrestricted except for regularity conditions, although I will take $v\left(1-L_{t}\right) \equiv\left(1-L_{t}\right)^{1-\nu} /(1-\nu)$ in the simulations below. ${ }^{4}$

\footnotetext{
${ }^{3}$ Although these models originate with Kydland and Prescott (1982), the version by King, Plosser, and Rebelo (1988) is more standard and generalizes more cleanly to multiple sectors.

${ }^{4}$ I will interpret $\sigma=1$ as corresponding to the utility kernel $\log C_{t}+v\left(1-L_{t}\right)$, which is more standard in the literature. In practice, whether $\sigma=1$ or $\sigma \neq 1$ has very little impact on my results, so long as the implied Frisch labor supply elasticities for the two specifications are similar.
} 
Equation (I-2) gives the economy's production function. Constant returns to scale and perfect competition are assumed, although I will discuss some implications of dropping these assumptions in section 3. The quantity $X_{t}$ is a deterministic trend in labor productivity, while $A_{t}$ is a stochastic, time-stationary process that represents exogenous shocks to the production technology.

The capital equation ( $\mathrm{I}-3)$ is standard: the capital stock depreciates at rate $\delta$ and is augmented by investment.

Finally, (I-4) is a balanced budget constraint for the government. If government purchases exceed (fall short of) income taxes, the remainder is made up through lumpsum taxation (transfers), and $T_{t}$ will be negative (positive).

The representative agent chooses paths for $\left\{L_{t}\right\}$ and $\left\{C_{t}\right\}$ that maximize (I-1) subject to the asset equation

$$
K_{t+1}=\left(1+r_{t}\right) K_{t}+\left((1-\tau) w_{t} L_{t}-C_{t}+T_{t}\right)
$$

and the transversality condition

$$
\lim _{t \rightarrow \infty} K_{t+1} / \prod_{s=0}^{t}\left(1+r_{s}\right) \geq 0
$$

taking as given the (exogenous) stochastic processes for $\left\{A_{t}\right\}$, and $\left\{G_{t}\right\}$, the histories of all relevant variables up to time 0 , and the stochastic future paths of the variables $w_{t} \equiv(1-\tau) A_{t} F_{L_{t}}, r_{t} \equiv(1-\tau) A_{t} F_{K_{t}}-\delta$, and $T_{t}$. A rational expectations equilibrium in this setting is a solution to the agent's problem, above, that takes as given the stochastic, aggregate time paths for $w_{t}, r_{t}$, and $T_{t}$ resulting from the agents' consumption and labor supply rules and equations (I-2) through (I-4).

\subsection{The Multi-Sector Model}

We may now generalize the model to incorporate multiple sectors. Analogous to the baseline one-sector model, it is assumed that each sector is characterized by perfect competition, constant returns to scale, and value-added production function $Y_{i t} \equiv A_{i t} K_{i t}^{1-\alpha_{i}} L_{i t}^{\alpha_{i}}$, $i=1, \ldots, n .^{5}$ There is assumed to be only one kind of capital that is used by all sectors of

\footnotetext{
${ }^{5}$ The trend term $X_{t}$ has been dropped from these equations for expository convenience; it will be reinstated in the formal presentation of the model below.
} 
the economy for production, just as there is only one type of labor. The capital stocks $K_{i t}$ are assumed to be fixed at the beginning of each period, just as is $K_{t}$ in the aggregate model. At time $t$ any shocks to the economy are realized, and labor $L_{i t}$ is adjusted by firms accordingly. I assume that labor is freely mobile both between sectors and into and out of the labor force; again, this is exactly analogous to the one-sector model. The assumptions that capital is fixed for one period while labor is freely mobile are realistic if we think of a period as being roughly one year in length, rather than one quarter. While labor market frictions are undoubtedly an important aspect of sectoral reallocation and unemployment, it will be shown in section 3 that they are not crucial for the points being made in this paper, and hence are ignored for clarity.

Production and consumption take place once the labor adjustment has been made. Each sector $i$ produces a characteristic good which has price $p_{i t}$, determined by supply and demand in that sector. Profit maximization, competitive markets, labor mobility, and the given capital stocks $K_{i t}$ imply:

$$
\begin{aligned}
& L_{i t}=A_{i t}^{1 /\left(1-\alpha_{i}\right)}\left(\frac{w_{t}}{\alpha_{i} p_{i t}}\right)^{-1 /\left(1-\alpha_{i}\right)} K_{i t} \\
& Y_{i t}=A_{i t}^{1 /\left(1-\alpha_{i}\right)}\left(\frac{w_{t}}{\alpha_{i} p_{i t}}\right)^{-\alpha_{i} /\left(1-\alpha_{i}\right)} K_{i t}
\end{aligned}
$$

At the end of each period, investment is executed, and the capital stocks $K_{i t}$ may be adjusted freely, up or down. This is again exactly analogous to the one-sector case. I abstract away from adjustment costs to capital here for the same reasons as above.

The multi-sector model is then specified as follows:

$$
\begin{aligned}
\text { Preferences: } U & \equiv \sum_{t=0}^{\infty} \beta^{t} \frac{C_{t}^{1-\sigma}}{1-\sigma} v\left(1-L_{t}\right) \\
\text { where } C_{t} & \equiv\left[\sum \eta_{i} C_{i t}^{(\theta-1) / \theta}\right]^{\theta /(\theta-1)} \\
P_{C t} & \equiv\left[\sum \eta_{i}^{\theta} p_{i t}^{1-\theta}\right]^{1 /(1-\theta)} \\
\text { Production: } Y_{i t} & =A_{i t} K_{i t}^{1-\alpha_{i}}\left(X_{t} L_{i t}\right)^{\alpha_{i}} \\
\text { with } K_{t} & \equiv \sum K_{i t} \\
L_{t} & \equiv \sum L_{i t} \\
Y_{t} & \equiv \sum p_{i t} Y_{i t}
\end{aligned}
$$




$$
\begin{gathered}
\text { Capital Stock: } K_{t+1}=(1-\delta) K_{t}+\frac{1}{P_{K t}}\left(Y_{t}-P_{C t} C_{t}-G_{t}\right) \\
\text { where } P_{K t} \equiv \sum \xi_{i} p_{i t} \text { is the price of one unit of } \\
\text { capital, defined to be a Leontief combination } \\
K \equiv \sum \xi_{i} \operatorname{good}_{i} .
\end{gathered}
$$

Government: $\quad \tau Y_{t}=G_{t}+T_{t}$

$$
\text { where } G_{t} \equiv \sum p_{i t} G_{i t}
$$

where I have normalized the price level by setting the GDP deflator (the price of a unit of "aggregate output") equal to unity in every period. The $p_{i t}$ are determined by supply and demand in each sector, so that $Y_{i t}=C_{i t}+I_{i t}+G_{i t}$. This yields the relationship

$$
A_{i t}^{1 /\left(1-\alpha_{i}\right)}\left(\frac{w_{t}}{\alpha_{i} p_{i t}}\right)^{-\alpha_{i} /\left(1-\alpha_{i}\right)} K_{i t}=C_{t}\left(\frac{p_{i t}}{\eta_{i} P_{C t}}\right)^{-\theta}+\frac{\xi_{i}}{P_{K t}}\left(Y_{t}-P_{C t} C_{t}-G_{t}\right)+G_{i t}
$$

whose derivation will be given below.

Model II is directly comparable to baseline Model I. For example, equations (II-1) yield the same set of aggregate preferences as the baseline model. Note that the CES utility kernel and price index $P_{C t}$ satisfy $P_{C t} C_{t}=\sum p_{i t} C_{i t}$ when the consumer chooses $C_{i t}$ optimally, so that $P_{C t}$ can be regarded as the true price of an "aggregate unit of consumption" $C_{t}$. Also note that not all goods need enter the utility function, since some of the $\eta_{i}$ may be set equal to zero.

Equations (II-2) specify the economy's production technology. It can be shown (see Appendix A for a derivation) for the special case $\alpha_{i}=\alpha$ for all $i$, that the economy's aggregate production function, derived from (II-2), is of the form $Y_{t}=A_{t} K_{t}^{1-\alpha} L_{t}^{\alpha}$, where

$$
A_{t} \equiv\left[\sum A_{i t}^{1 /(1-\alpha)} p_{i t}^{1 /(1-\alpha)} \frac{K_{i t}}{K_{t}}\right]^{1-\alpha}
$$

The direct correspondence to baseline Model I is then obvious, the only difference being that here we have provided microeconomic foundations for $A_{t}$, making aggregate technology endogenous rather than exogenous. ${ }^{6,7}$

\footnotetext{
${ }^{6}$ The aggregate production function $Y_{t}=A_{t} K_{t}^{1-\alpha} L_{t}^{\alpha}$, with $A_{t}$ as in equation (9), also holds to first order for small variations in the $\alpha_{i}$ about some central $\alpha$. When the $\alpha_{i}$ are completely unrestricted, however, the economy's aggregate production function is more complicated, and the correspondence to model I is less direct. See Appendix A for details.

${ }^{7}$ Note that when we measure effects on aggregate productivity below, we will measure it directly as $\hat{A}_{t}=\hat{Y}_{t}-\alpha \hat{L}_{t}-(1-\alpha) \hat{K}_{t}$, rather than use equation (9), since the direct approach is valid regardless of the values of the $\alpha_{i}$ (the aggregate quantity $\alpha$ here is defined as labor's share in aggregate output). This measure of $A_{t}$ is equivalent to (9) when all $\alpha_{i}=\alpha$.
} 
Equation (II-3) is similarly very close to (I-3), the only difference being that in Model II we must keep track of variation in the price of a unit of capital relative to the price of a unit of output. Capital is defined here as a Leontief combination of the different sectoral goods because this method is both very tractable and general enough for the purposes of this paper. For example, it encompasses the case of one investment good and $n-1$ consumption goods by setting $\xi_{i}=0$ for all $i \neq n .{ }^{8}$ Note that we may set the steady-state $P_{K}=1$ by scaling the $\xi_{i}$ appropriately.

Equation (II-4) is the government's balanced budget constraint. It is identical to (I-4), except that here government purchases may be distributed across sectors in an unequal fashion.

Finally, (II-5) is a straightforward derivation from the principles discussed so far. It consists of a system of $n$ equations $Y_{i t}=C_{i t}+I_{i t}+G_{i t}$, which together determine the $n$ prices $p_{i t}$ given the other variables of the system. Substituting in for $Y_{i t}$ from equation (8), $C_{i t}$ from the utility-maximizing relation $C_{i t}=C_{t}\left(p_{i t} / \eta_{i} P_{C t}\right)^{-\theta}$, and $I_{i t}$ from the relation $I_{i t}=\left(\xi_{i} / P_{K t}\right)\left(Y_{t}-P_{C t} C_{t}-G_{t}\right)$ yields (II-5).

A competitive equilibrium in Model II is defined in a manner exactly analogous to Model I. The representative agent's asset equation is now

$$
K_{t+1}=\left(1+r_{t}\right) K_{t}+\frac{1}{P_{K t}}\left((1-\tau) w_{t} L_{t}-P_{C t} C_{t}+T_{t}\right)
$$

and the transversality condition (I-6) carries over verbatim. The representative agent thus solves essentially the same maximization problem as before, except for the additional variation in the prices $\left\{P_{C t}\right\}$ and $\left\{P_{K t}\right\}$, and a change in the definition of $r_{t}$ to $r_{t} \equiv$ $\left(1 / P_{K t}\right)(1-\tau) A_{t} F_{K t}-\delta$, required for $(\mathrm{I}-5)^{\prime}$ to agree with the aggregate constraint (II-3).

In multi-sector Model II, the agent also must allocate consumption and investment across sectors once the overall levels of $C_{t}$ and $L_{t}$ have been decided upon. Allocating the $C_{i t}$ is trivial, given the agent's desired $C_{t}$ and the economy's prices $p_{i t}$, and at the individual level it does not matter how the $K_{i, t+1}$ are chosen, since the expected returns to capital

\footnotetext{
${ }^{8}$ Some authors (Galí (1994), Horvath (1997b)) have used a CES aggregator for the capital good. This leads, however, to the thorny issue of whether one should reshuffle the entire capital stock every time relative prices change. For example, if we define $I_{t} \equiv\left[\sum \xi_{i} I_{i t}^{\rho}\right]^{1 / \rho}$, as these authors do, then a change in relative prices alters the composition of an optimal unit of investment. It is then hard to justify an equation such as $K_{t+1}=(1-\delta) K_{t}+I_{t}$, since the composition of investment has changed. Yet if we define instead $K_{t} \equiv\left[\sum \xi_{i} K_{i t}^{\rho}\right]^{1 / \rho}$, then firms want to completely reshuffle the distribution of the $K_{i t}$ every time relative prices change. Both of these approaches are thus very problematic.
} 
are equalized across all sectors by investment arbitrage. To determine the macroeconomic distribution of the $K_{i, t+1}$, we calculate the expected returns to capital in each of the $n$ sectors and equalize them.

As before, a rational expectations equilibrium is a solution to the agent's problem (maximization of (II-1) subject to $(\mathrm{I}-5)^{\prime}$ and (I-6)), taking as given the stochastic, aggregate time paths for $w_{t}, r_{t}, T_{t}, P_{C t}$, and $P_{K t}$ that result from the agents' consumption and labor supply rules, equations (II-2) through (II-5), and the sectoral profit-maximization condition (7).

\subsection{Solution Method}

The dynamic programming aspects of models I and II are sufficiently complex that closedform solutions cannot be obtained in general. Thus, we must turn to numerical methods. The solution algorithm of this paper follows closely the log-linearization procedure of King, Plosser, and Rebelo (1987, 1988), generalized to a multi-sector setting, with one notable exception: because the variation in sectoral output, employment, and prices (and later, capital utilization) are potentially large at the sectoral level, and because I need to allow for the possible importance of second-order effects in order to demonstrate that they are small, a solution procedure that linearizes all variables from the outset is suspect. I resolve this problem by solving the model nonlinearly for the first several periods. Thus, if a shock hits the economy in period $t$, the equations of the model are linearized only for periods $t+k$ and beyond, for some positive integer $k$, allowing for ready solution of the infinite-horizon problem while still preserving the possibly important nonlinearities of the model's equations in periods $t$ through $t+k-1$. By choosing $k$ appropriately, we can ensure that the effects of the initial shock have died down sufficiently that a linearization procedure for these later periods is valid. This solution algorithm is described in more detail in Appendix B.

\section{Limits to the Effects of Sectoral Reallocation}

A reallocation of labor and production across sectors in the model above could be due to changes in tastes (the $\eta_{i}$ ), changes in exogenous government purchases $G_{i t}$, changes in the Leontief composition of the investment good (the $\xi_{i}$ ), or changes in sectoral technology $A_{i t}$. 
A reallocative shock from any of these sources will typically have a substantial impact on the aggregate variables of the system. It should be noted, however, that there are certain empirical features of business cycles that sectoral reallocations cannot explain, at least not in a perfectly competitive framework. These limitations relate primarily to aggregate productivity and related quantities (e.g., real wages, aggregate increasing returns to scale).

As a quick demonstration of these limits, assume first that a general economic model with sectoral production functions $Y_{i t}=A_{i t} F_{i}\left(K_{i t}, L_{i t}\right)$ is characterized by perfect competition, constant returns to scale, free mobility of labor $L_{i t}$, and capital stocks $K_{i t}$ that are fixed in the short run. The model of the previous section possesses all of these traits, although it is by no means the only one. Let $\alpha_{i}$ denote labor's share $w L_{i} / p_{i} Y_{i}$ in sector $i$, and $\alpha$ labor's aggregate share, $w L / Y$ (the absence of a time subscript on a variable denotes its steady-state value). Define $L_{t} \equiv \sum L_{i t}$ and $Y_{t} \equiv \sum p_{i} Y_{i t}$. Then, perturbing the economy from steady state, we have by the Solow (1957) decomposition:

$$
\begin{aligned}
\hat{A}_{t} & =\hat{Y}_{t}-\alpha \hat{L}_{t} \\
& =\sum \frac{p_{i} Y_{i}}{Y} \hat{Y}_{i t}-\alpha \hat{L}_{t} \\
& =\sum \frac{p_{i} Y_{i}}{Y} \hat{A}_{i t}+\sum \frac{p_{i} Y_{i}}{Y} \alpha_{i} \hat{L}_{i t}-\alpha \hat{L}_{t} \\
& =\sum \frac{p_{i} Y_{i}}{Y} \hat{A}_{i t}+\sum \frac{w L_{i}}{w L} \alpha \hat{L}_{i t}-\alpha \sum \frac{L_{i}}{L} \hat{L}_{i t} \\
& =\sum \frac{p_{i} Y_{i}}{Y} \hat{A}_{i t}
\end{aligned}
$$

Reallocative effects, stemming from the movement of labor across sectors, can have no firstorder impact on aggregate productivity. The only first-order effects come from movements in the exogenous sectoral technology terms $A_{i t}$.

The intuition for this result is extremely simple. In steady state, the marginal products of labor in different sectors are equalized under the given assumptions. Relative to steady state, then, a shift of labor from one sector to another can have no first-order effect on the aggregate quantity of output. But in DSGE, a model is presumed to be perturbed from steady state, or to be lying within a neighborhood of its steady state at all times.

The simplicity of the argument reflects its generality. Introducing additional inputs or any combination of lags or adjustment costs to the mobility of different factors, the exact same Solow calculation still carries through. The intuition is identical-no matter what the frictions to factor mobility, so long as they are finite and markets are competitive, all 
marginal products will come into equality in steady state. A reallocation can then have no first-order effect on aggregate output relative to aggregate inputs, and thus on aggregate productivity, labor productivity and real wages, and observed aggregate increasing returns to scale. We may state this somewhat more concretely as follows:

Proposition: Let $\mathcal{Y}$ be an economic model with outputs $Y_{i j t}=A_{i j t} F_{i j}\left(L_{i n t}, X_{i k t}\right)$, where $i=1, \ldots, I$ indexes sectors, $n=1, \ldots, N$ indexes primary inputs $L_{i n t}, j, k=1, \ldots, J$ indexes produced goods $Y_{i j t}$ and intermediate inputs $X_{i k t}$, and $t$ indexes time (with a lack of time subscript indicating a steady-state value). The production functions $F_{i j}$ are assumed to satisfy the typical regularity conditions and be homogeneous of degree one, and the model economy is assumed to be perfectly competitive, with goods prices $p_{j t}$ and primary input prices $w_{n t}$. Define $Y_{t} \equiv \sum_{i, j} p_{j t} Y_{i j t}-\sum_{i, k} p_{k t} X_{i k t}, L_{n t} \equiv \sum L_{i n t}, s_{n} \equiv w_{n} L_{n} / Y$, and $\hat{A}_{t} \equiv \hat{Y}_{t}-\sum s_{n} \hat{L}_{n t}$. Then changes in inputs have no first-order effect on $\hat{A}_{t}$, regardless of any combination of adjustment costs to inputs, adjustment lags to inputs, and the extent of intermediate input linkages between sectors.

Proof: Note that each sector $i$ may produce several goods $j$. We have:

$$
\begin{aligned}
\hat{A}_{t}= & \hat{Y}_{t}-\sum_{n} s_{n} \hat{L}_{n t} \\
= & \sum_{i, j} \frac{p_{j} Y_{i j}}{Y} \hat{Y}_{i j t}-\sum_{i, k} \frac{p_{k} X_{i k}}{Y} \hat{X}_{i k t}-\sum_{i, n} \frac{w_{n} L_{i n}}{Y} \hat{L}_{i n t} \\
= & \sum_{i, j} \frac{p_{j} Y_{i j}}{Y} \hat{A}_{i j t}+\sum_{i, j, n} \frac{p_{j} Y_{i j}}{Y} \frac{A_{i j} L_{i n}}{Y_{i j}} \frac{\partial F_{i j}}{\partial L_{i n}} \hat{L}_{i n t}+\sum_{i, j, k} \frac{p_{j} Y_{i j}}{Y} \frac{A_{i j} X_{i k}}{Y_{i j}} \frac{\partial F_{i j}}{\partial X_{i k}} \hat{X}_{i k t} \\
& \quad-\sum_{i, k} \frac{p_{k} X_{i k}}{Y} \hat{X}_{i k t}-\sum_{i, n} \frac{w_{n} L_{i n}}{Y} \hat{L}_{i n t} \\
= & \sum_{i, j} \frac{p_{j} Y_{i j}}{Y} \hat{A}_{i j t}
\end{aligned}
$$

The presence of adjustment costs or lags, or intermediate input linkages, may alter the responses of the $\hat{L}_{i n t}$ or $\hat{X}_{i k t}$ to shocks, but does not affect their cancellation in the above derivation in any way. This completes the proof: any first-order movements in $\hat{A}_{t}$ can come only from the weighted average of movements in the $\hat{A}_{i j t}$.

The point has been frequently missed in the literature. For example, Phelan and Trejos (1995) declare in their abstract that "the frictions we study can cause one time increases in productivity concentrated in one sector to be mistaken for a series of smaller, correlated aggregate productivity shocks" (title page). As demonstrated above, any effects of reallocation (with frictions or without) on aggregate productivity in those authors' 
perfectly competitive model must be second-order. The reallocations caused by their shock can neither dampen aggregate productivity movement in the first period nor lead to smaller, persistent movements in aggregate productivity in later periods (to first order). An examination of the size of the sectoral technology shock to which they refer confirms this assertion: the shock is a $24 \%$ leap in productivity in the sector in question, the sector itself comprising one third of the aggregate economy. The reallocative effect on aggregate productivity - the component beyond the direct average $\sum\left(p_{j} Y_{i j} / Y\right) \hat{A}_{i j t}$-is less than $2 \%$. The size of this effect will decrease more than linearly as one decreases the size of the shock.

Davis (1987) makes a similar claim regarding the real wage. In his model with labor market frictions, "A close match between the desired and actual labor-force allocation implies that market goods will be valued highly... and the real wage will be high" (p. 386). The fact that "a close match" and "a poor match" are measured in terms of absolute discrepancies regardless of their sign immediately suggests that the effect is second-order. In fact, this is the case: under perfect competition, $\mathrm{MPL}=\hat{A}+\partial \hat{F / \partial L}$, and we have already shown that changes in inputs have no first-order effect on $\hat{A}$. Any first-order changes in the marginal product of labor, then, can come only from changes in the aggregate quantity of labor input $L$ acting through $\partial F / \partial L$. Any reallocative effects are second-order.

The implications for the intermediate input linkage models of Long and Plosser (1983) and Horvath (1997a,b) are also significant. Although these papers only make claims about the ability of sectoral shocks to explain movements in aggregate output, it is important to note that they have little or no ability to explain movements in aggregate productivity, other than as a direct weighted average of changes in sectoral productivities. As the number of sectors increases, this effect tends toward zero, by the Law of Large Numbers, even more so than with output, since there are no "feed through" effects that arise from intermediate input linkages (where an increase in the output of one good leads to increases in the outputs of others who use it as an input to production). Thus, the model of Long and Plosser will never match one of the key empirical regularities of the business cycle, procyclical productivity. Horvath demonstrates a postponement of the LLN effect using a class of "sparse" intermediate input linkages, but by what we have shown above, it becomes immediately clear that his results apply to movements in output only - the change in aggregate productivity in his perfectly competitive model will always be the simple weighted average of the changes in sectoral productivities (to first order), with no 
postponement of the LLN whatsoever. ${ }^{9}$

Sectoral reallocations can in fact have important effects on aggregate productivity, labor productivity and real wages, and observations of aggregate increasing returns to scale. All that is required is a wedge in the model that drives the marginal products of inputs in different sectors apart in steady state. Such a wedge is introduced by Basu and Fernald (1997a,b) and Basu, Fernald, and Horvath (1997) in the form of imperfect competition and markups of price over marginal cost. Introducing markups $\mu_{i}$ into the exercise above, and letting $\mu$ denote some measure of an economywide, average markup, we arrive at a Hall (1988) decomposition along the following lines:

$$
\begin{aligned}
\hat{A}_{t} & =\hat{Y}_{t}-\mu \alpha \hat{L}_{t} \\
& =\sum \frac{p_{i} Y_{i}}{Y} \hat{A}_{i t}+\sum \frac{p_{i} Y_{i}}{Y} \mu_{i} \alpha_{i} \hat{L}_{i t}-\mu \alpha \hat{L}_{t} \\
& =\sum \frac{p_{i} Y_{i}}{Y} \hat{A}_{i t}+\sum \frac{w L_{i}}{w L} \mu_{i} \alpha \hat{L}_{i t}-\mu \alpha \sum \frac{L_{i}}{L} \hat{L}_{i t} \\
& =\sum \frac{p_{i} Y_{i}}{Y} \hat{A}_{i t}+\alpha \sum\left(\mu_{i}-\mu\right) \hat{L}_{i t}
\end{aligned}
$$

Thus, a reallocation of labor from a low-markup to a high-markup sector yields a firstorder increase in aggregate productivity. Note that the crucial requirement here is not that markups in the economy exist, but rather that they differ across sectors. However, if these differences in markups (or equivalently, differences in returns to scale, since profits are a tiny fraction of output) ${ }^{10}$ are relatively small (say 5-10\%), then the effects of reallocation on aggregate productivity and related quantities will be correspondingly small.

Two final points should be made regarding the generation of first-order effects through reallocation. First, it is important to note that differences in productivity levels across sectors have no effect whatsoever. The reason for this is that, in an equilibrium model, differences in productivity levels are completely offset by differences in steady-state product prices - if $A_{1}$ is twice as large as $A_{2}$, then $p_{1}$ must be half as large as $p_{2}$; otherwise, profits can be made by moving capital and labor from sector 2 to sector 1 . Levels of $A_{i}$ are thus

\footnotetext{
${ }^{9}$ Some other methods of circumventing the Law of Large Numbers do apply to aggregate productivity, however. The "implementation cycles" approach of Shleifer (1986) is one example.

${ }^{10}$ Define returns to scale $\gamma\left(K_{t}, L_{t}, M_{t}\right)$, for an arbitrary production function with inputs $K, L$, and $M$ and output $Y$, by $\gamma\left(K_{t}, L_{t}, M_{t}\right) \equiv(\partial \log Y / \partial \log K)+(\partial \log Y / \partial \log L)+(\partial \log Y / \partial \log M)$. The markup $\mu\left(K_{t}, L_{t}, M_{t}\right)$ of price over marginal cost equals $(p / w) \partial Y / \partial L$, with similar expressions for the other inputs. Substituting yields $\gamma=\mu\left(1-s_{\pi}\right)$, where $s_{\pi}$ is the share of output not paid to the inputs (using a "required return to capital" to calculate the share paid to capital). Basu and Fernald (1997a) put an upper bound on $s_{\pi}$ of .03 .
} 
essentially nothing more than a choice of units, which are completely neutral with respect to aggregate output, $Y_{t}=\sum p_{i t} Y_{i t}$.

Second, the absence of first-order effects on aggregate productivity does not preclude first-order effects on other aggregate quantities, in particular labor and output. Clearly, if there are adjustment costs or search lags to the shifting of labor across sectors, then persistent reallocations of demand will result in first-order decreases in the total quantity of labor employed, as the adjustment costs or lags are incurred and labor is shifted. This effect has been emphasized by Rogerson (1988), Hamilton (1986), and Davis (1987), among others. The effects on aggregate productivity are second-order because the declines in labor input are matched to first order by declines in output (multiplied by labor's share). The effects on aggregate labor productivity and the real wage are first-order (and countercyclical) because the effect on $\hat{L}$ is first-order; beyond this channel, operating through aggregate $\hat{L}$ and $\partial F / \partial L$, the reallocation has no first-order effects, as was demonstrated above.

\subsection{The Importance of Second-Order Effects}

One may question whether second-order effects in these models are not themselves important. Although shocks to variables in the aggregate economy result in movements of only a few percentage points, so the argument goes, sectoral shocks may be much larger. In principle this argument is quite valid; in practice, however, it tends to play only a minor role for shocks and sector sizes that are calibrated to actual U.S. data.

Consider, for example, the case of Cobb-Douglas production functions with inputs of capital and labor. The effects of changes in labor on sectoral output, to second order, are then:

$$
\begin{aligned}
Y_{i t}=Y_{i} & +A_{i} F_{K}\left(K_{i t}-K_{i}\right)+A_{i} F_{L}\left(L_{i t}-L_{i}\right)+\left(A_{i t}-A_{i}\right) F \\
& +A_{i} F_{K K}\left(K_{i t}-K_{i}\right)^{2}+A_{i} F_{L L}\left(L_{i t}-L_{i}\right)^{2}+2 A_{i} F_{K L}\left(K_{i t}-K_{i}\right)\left(L_{i t}-L_{i}\right)
\end{aligned}
$$

Assuming capital is fixed in the short run, the second-order terms reduce simply to $-\alpha_{i}(1-$ $\left.\alpha_{i}\right) Y_{i}\left(\hat{L}_{i t}\right)^{2}$, which we then multiply by $p_{i} / Y$ to determine the percentage contribution to aggregate output. The empirical difficulties lie in the fact that the sector size $p_{i} Y_{i} / Y$ decreases as the empirically plausible magnitude of $\hat{L}_{i t}$ increases; if the relationship between sector size and the variance of input movements is (inverse) linear, the effects will be exactly 
offsetting. Clearly, this relationship is extremely important for determining the plausible contribution of sectoral shocks to aggregate fluctuations, and more research in this area would be welcome.

Currently, the best example of a large, narrowly-focused shock to the economy is probably military purchases. The standard deviation of these shocks over the post-War period has been roughly $4 \%$ of total government purchases (treating annual government purchases as an AR(1) process, and including the Korean and Vietnam Wars), and these changes are very largely concentrated in sectors that make up roughly $7 \%$ of the U.S. economy. These numbers are in general agreement with those put forth by Ramey and Shapiro (1997). Using the fact that government purchases are roughly $20 \%$ of GDP, and plugging these numbers into the expression above, we arrive at second-order effects on aggregate output of roughly $-(.66)(.33)(.07)(.04 \cdot .2 / .07)^{2}=-.0002$, or .02\% . Doubling the size of the shock raises the effect to $.08 \% .{ }^{11}$ Clearly, we need examples of larger shocks to sectors of the economy if we are to find plausible second-order effects of reallocation in models such as these.

\section{Variable Capital Utilization}

This section postulates that differences in the cylical utilization of capital across sectors - as opposed to differences in sectoral markups and returns to scale - are a source of first-order aggregate productivity movement in models of sectoral reallocation. There are several reasons why variable capital utilization should be regarded as a superior approach. First, numerous empirical studies have found that, once variable capital utilization is controlled for, there is very little evidence of increasing returns to scale (and hence markups) at the sectoral or aggregate level (Burnside, Eichenbaum, and Rebelo (1995,1996), Basu (1996)). Plant-level studies in the manufacturing sector have also failed to turn up significant evidence of increasing returns to scale (Baily, Hulten, and Campbell (1992), Griliches and Ringstad (1971)). In contrast, numerous studies document the empirical importance of

\footnotetext{
${ }^{11}$ Relaxing the Cobb-Douglas assumption has little effect on the magnitudes of these estimates; one would have to assume that the sectoral production functions have a curvature term $F_{L L}$ that is an order of magnitude larger than Cobb-Douglas to generate quantitatively significant results. Allowing for additional inputs also has little effect, since the fall in labor's share that results largely offsets any gains from the additional second-order terms.
} 
variable capital utilization over the business cycle (Shapiro (1996), Burnside, Eichenbaum, and Rebelo (1995), Basu (1996), to name just a few). In addition, it is very reasonable to expect nonmanufacturing sectors such as Services, Agriculture, and Wholesale \& Retail Trade to exhibit relatively little variation in capital utilization, while it is known that most durables manufacturing industries vary their capital use substantially-according to Shapiro (1996), over $40 \%$ of the cyclical variation in manufacturing employment comes from work on evening and late shifts (Shapiro also presents evidence that cyclical variation in the workweek of capital varies greatly even across sectors within manufacturing). Thus, the empirical support not just for variable capital utilization, but for differences in the cyclicality of utilization across sectors, is quite strong. It thus offers a firmer foundation upon which to base a reallocations model.

Variable capital utilization has also been introduced into one-sector DSGE models with much success. Burnside and Eichenbaum (1996) demonstrate that variable capital utilization greatly improves the ability of a typical one-sector model to amplify and propagate exogenous technology shocks and match key moments of the data. In a multi-sector framework, we will gain from these benefits as well, but in addition demonstrate the importance of a reallocative channel that differences in utilization across sectors makes possible. This leads to further amplification and propagation of shocks that the one-sector model (with or without capital utilization) does not possess.

\subsection{The Multi-Sector Model with Capital Utilization}

The assumptions of this model are essentially the same as those for the multi-sector model of section 2: namely, contant returns to scale in every sector, perfect competition, free mobility of labor, and capital stocks fixed for one period and freely mobile afterward. Adjustment costs to labor and capital would add persistence to the model, but otherwise would not alter the reallocative effects that are the emphasis of this paper.

We allow for sectoral capital utilization in the model as follows:

$$
Y_{i t} \equiv A_{i t}\left(U_{i t}^{\omega_{i}} K_{i t}\right)^{1-\alpha_{i}} L_{i t}^{\alpha_{i}}
$$

The coefficients $\omega_{i} \in[0,1]$ denote the effectiveness of capital utilization within each sector: low (high) values of $\omega_{i}$ correspond to small (large) returns to the utilization of capital, 
which leads utilization to vary relatively less (more) in response to shocks to the sector. Previous studies of variable capital utilization have simply taken $\omega_{i}=1$, the implicit assumption being that capital is equally productive no matter what time of day or week it is used. Allowing for $\omega_{i}<1$ permits us to relax this assumption. For example, capital in the Retail Trade or Services sector is probably significantly less productive at night, when many customers are at home or asleep; it thus might be regarded as having an $\omega_{i}$ much closer to 0 than to 1 . Agriculture also presumably depends heavily upon daylight and the weather when making use of its capital, so that additional utilization will likely be forced to take place under less than optimal circumstances, again resulting in $\omega_{i}<1$. In contrast, capital in the Durables Manufacturing sector is more likely to be equally productive no matter when it is used, corresponding to $\omega_{i}=1 .{ }^{12,13}$ Note that for any value of $\omega_{i}$, units will be chosen below so as to set $U_{i}=1$ in steady state, so that the parameter is important only for utilization at the margin; the limiting case $\omega_{i}=0$ then corresponds to the situation where utilization does not vary at the margin at all, resulting in $U_{i t}=1$ at all times $t .{ }^{14}$

Utilization must have some cost if it is to be finite in equilibrium. Following Greenwood, Hercowitz, and Huffman (1988) and Burnside and Eichenbaum (1996), among others, this cost will be taken directly out of the capital stock, in the form of increased depreciation:

$$
\delta_{i t} \equiv \delta_{i}\left(U_{i t}\right)
$$

where $\delta_{i}$ is an increasing function of $U_{i t}$.

Profit maximization by firms, and the short-run fixity of capital $K_{i t}$, yield a set of equations very similar to the basic multi-sector model:

$$
L_{i t}=A_{i t}^{1 /\left(1-\alpha_{i}\right)}\left(\frac{w_{t}}{\alpha_{i} p_{i t}}\right)^{-1 /\left(1-\alpha_{i}\right)} U_{i t}^{\omega_{i}} K_{i t}
$$

\footnotetext{
12 In this framework, a "continuous process" industry (Shapiro (1996)) also corresponds to $\omega_{i}=1$. Here, it may be optimal to run capital in any given plant around the clock, but to the extent that such an industry desires to vary its utilization cyclically, it may do so either by mothballing entire plants, or by bringing entire plants back online. To the extent that mothballed plants are less productive than operational ones, $\omega_{i}$ will be less than unity, but I ignore this consideration here.

13 There is actually no need to restrict $\omega_{i} \leq 1$ in the model so long as the cost parameter $\phi_{i}>\omega_{i}$; however, values of $\omega_{i}$ much greater than unity imply implausiblly large increasing returns to capital utilization.

${ }^{14}$ Strictly speaking, we must also let the cost parameter $\phi_{i}$ tend to $\infty$ to achieve the limiting result $U_{i t}=1$ for all times $t$. This is because in the specification below, costs also tend to 0 as $\omega_{i}$ tends to 0 , so that simply letting $\omega_{i} \rightarrow 0$ is not sufficient to guarantee a fixed level of utilization. In the implementation of the model, below, the utilization feature is "turned off" for some simulations by setting $\omega_{i}=0$ and $\phi_{i}$ to a very large number, for each sector.
} 


$$
Y_{i t}=A_{i t}^{1 /\left(1-\alpha_{i}\right)}\left(\frac{w_{t}}{\alpha_{i} p_{i t}}\right)^{-\alpha_{i} /\left(1-\alpha_{i}\right)} U_{i t}^{\omega_{i}} K_{i t}
$$

The optimal choice of $U_{i t}$ is determined by equating the marginal benefit of utilization, $\omega_{i}\left(1-\alpha_{i}\right) p_{i t} Y_{i t} / U_{i t}$, to its marginal cost, $\delta_{i}^{\prime} K_{i t} / P_{K t}$. This yields:

$$
U_{i t} \delta_{i}^{\prime}=\omega_{i}\left(1-\alpha_{i}\right) \frac{p_{i t}}{P_{K t}} \frac{Y_{i t}}{K_{i t}}
$$

Define:

$$
\delta_{i}\left(U_{i t}\right) \equiv \delta_{0 i}+\frac{\delta_{1 i}}{\phi_{i}} U_{i t}^{\phi_{i}}
$$

We require $\phi_{i}>\omega_{i}$ to ensure that the equilibrium $U_{i t}$ is increasing in the relative price $p_{i t}$ and technology $A_{i t}$. Equation (14) becomes:

$$
\delta_{1 i} U_{i t}^{\phi_{i}}=\omega_{i}\left(1-\alpha_{i}\right) \frac{p_{i t}}{P_{K t}} \frac{Y_{i t}}{K_{i t}}
$$

Plugging in for $Y_{i t}$ from equation (13) yields:

$$
U_{i t}=\left(\frac{\omega_{i}\left(1-\alpha_{i}\right)}{\delta_{1 i}}\right)^{1 /\left(\phi_{i}-\omega_{i}\right)}\left(\frac{p_{i t}}{P_{K t}}\right)^{1 /\left(\phi_{i}-\omega_{i}\right)} A_{i t}^{1 /\left(1-\alpha_{i}\right)\left(\phi_{i}-\omega_{i}\right)}\left(\frac{w_{t}}{\alpha_{i} p_{i t}}\right)^{-\alpha_{i} /\left(1-\alpha_{i}\right)\left(\phi_{i}-\omega_{i}\right)}
$$

Note that we can choose units (through suitable choices of $A_{i}$ and $\delta_{1 i}$ ) such that steadystate utilization $U_{i}=1$ in equilbrium. From equation (16) we then have, in steady state,

$$
\delta_{1 i}=\frac{\omega_{i} r_{\mathrm{K}}}{P_{K}}
$$

where $r_{\mathrm{K}}$ denotes the real steady-state marginal product of capital (equal across sectors). Also,

$$
\delta_{0 i}+\frac{\delta_{1 i}}{\phi_{i}}=\bar{\delta}
$$

where $\bar{\delta}$ is the steady-state depreciation rate of capital, assumed here to be $10 \%$ per year. Equations (18) and (19) thus pin down the values of $\delta_{0 i}$ and $\delta_{1 i}$ given the other parameters of the system.

We can now specify the complete multi-sector model with capital utilization as follows:

$$
\begin{gathered}
\text { Preferences: } U \equiv \sum_{t=0}^{\infty} \beta^{t} \frac{C_{t}^{1-\sigma}}{1-\sigma} v\left(1-L_{t}\right) \\
\text { where } C_{t} \equiv\left[\sum \eta_{i} C_{i t}^{(\theta-1) / \theta}\right]^{\theta /(\theta-1)} \\
P_{C t} \equiv\left[\sum \eta_{i}^{\theta} p_{i t}^{1-\theta}\right]^{1 /(1-\theta)}
\end{gathered}
$$




$$
\begin{aligned}
\text { Production: } Y_{i t} & =A_{i t}\left(U_{i t}^{\omega_{i}} K_{i t}\right)^{1-\alpha_{i}}\left(X_{t} L_{i t}\right)^{\alpha_{i}} \\
\text { with } K_{t} & =\sum K_{i t} \\
L_{t} & =\sum L_{i t} \\
Y_{t} & \equiv \sum p_{i t} Y_{i t} \\
\text { Capital Stock: } K_{t+1} & =\left(1-\delta_{t}\right) K_{t}+\frac{1}{P_{K t}}\left(Y_{t}-P\right. \\
\text { where } \delta_{t} & \equiv \sum \frac{K_{i t}}{K_{t}} \delta_{i t}, \quad \delta_{i t} \equiv \delta_{0 i}+\delta_{1 i} \\
P_{K t} & \equiv \sum \xi_{i} p_{i t} \\
\tau Y_{t} & =G_{t}+T_{t} \\
\text { Government: } &
\end{aligned}
$$

The roman numeral III will be used to denote a one-sector version of the model with capital utilization-i.e., model IV with $n=1$ and $\omega_{1}=1 .^{15}$

As before, the $p_{i t}$ are determined by supply and demand in each sector, so that $Y_{i t}=C_{i t}+I_{i t}+G_{i t}$. From (13) and the fact that $C_{i t}=C_{t}\left(p_{i t} / \eta_{i} P_{C t}\right)^{-\theta}$ under utility maximization, this becomes:

$$
A_{i t}^{1 /\left(1-\alpha_{i}\right)}\left(\frac{w_{t}}{\alpha_{i} p_{i t}}\right)^{-\alpha_{i} /\left(1-\alpha_{i}\right)} U_{i t}^{\omega_{i}} K_{i t}=C_{t}\left(\frac{p_{i t}}{\eta_{i} P_{C t}}\right)^{-\theta}+\frac{\xi_{i}}{P_{K t}}\left(Y_{t}-P_{C t} C_{t}-G_{t}\right)+G_{i t}
$$

A competitive, rational expectations equilibrium here is exactly analogous to the multi-sector model of section 2: a solution to the agent's problem posed by (IV-1), (I-5)', and (I-6), taking as given the stochastic, aggregate time paths for $w_{t}, r_{t}, T_{t}, P_{C t}$, and $P_{K t}$ that result from the agents' consumption and labor supply rules, equations (IV-2) through (IV-5), and the sectoral profit-maximization conditions (12) and (17).

The only new wrinkles in this system of equations is the introduction of the capital utilization term into (IV-2) and the time-varying depreciation rate in (IV-3). It is assumed that agents are representative, and hence hold capital assets distributed across sectors in the same proportions as is capital in the aggregate economy, so that the given average

\footnotetext{
${ }^{15}$ Note that for this one-sector special case, with $\omega=1$, model IV reduces exactly to the capitalutilization framework of Burnside and Eichenbaum (1996). The approach taken here is thus a proper generalization of their work.
} 
depreciation rate is the appropriate one for computing agents' realized net rate of return on assets.

\subsection{Reallocation, Capital Utilization, and Aggregate Productivity}

Once variable capital utilization has been introduced into the model, the effects of sectoral reallocation on aggregate productivity become first-order. This can be seen as follows. First, define

$$
\hat{A}_{t} \equiv \hat{Y}_{t}-\alpha \hat{L}_{t}-\omega(1-\alpha) \hat{U}_{t}
$$

where $\omega$ is some measure of the average productivity of utilization in the economy. The inclusion of a $\hat{U}_{t}$ term in (20) implies that at least some measure of aggregate utilization is being taken into account when aggregate productivity is calculated; if this is not the case (e.g., $\omega$ is set equal to 0 ), then apparent aggregate productivity movement will be correspondingly greater than is demonstrated here. Assume $Y_{i t}=A_{i t} F_{i}\left(U_{i t}^{\omega_{i}} K_{i t}, L_{i t}\right)$, as in the model above, and let $U_{t} \equiv \sum\left(K_{i t} / K_{t}\right) U_{i t}$. We then have:

$$
\begin{aligned}
\hat{A}_{t} & =\sum \frac{p_{i} Y_{i}}{Y} \hat{A}_{i t}+\sum \frac{p_{i} Y_{i}}{Y} \alpha_{i} \hat{L}_{i t}+\sum \frac{p_{i} Y_{i}}{Y} \omega_{i}\left(1-\alpha_{i}\right) \hat{U}_{i t}-\alpha \hat{L}_{t}-\omega(1-\alpha) \hat{U}_{t} \\
& =\sum \frac{p_{i} Y_{i}}{Y} \hat{A}_{i t}+\sum \frac{p_{i} Y_{i}}{Y} \omega_{i}\left(1-\alpha_{i}\right) \hat{U}_{i t}-\omega(1-\alpha) \hat{U}_{t} \\
& =\sum \frac{p_{i} Y_{i}}{Y} \hat{A}_{i t}+(1-\alpha) \sum \frac{K_{i}}{K} \omega_{i} \hat{U}_{i t}-\omega(1-\alpha) \hat{U}_{t} \\
& =\sum \frac{p_{i} Y_{i}}{Y} \hat{A}_{i t}+(1-\alpha) \sum \frac{K_{i}}{K} \omega_{i} \hat{U}_{i t}-\omega(1-\alpha) \sum \frac{K_{i}}{K} \hat{U}_{i t}, \\
& =\sum \frac{p_{i} Y_{i}}{Y} \hat{A}_{i t}+(1-\alpha) \sum \frac{K_{i}}{K}\left(\omega_{i}-\omega\right) \hat{U}_{i t}
\end{aligned}
$$

A reallocation from a sector with little tendency to vary capital utilization to one with a greater tendency to do so will lead to a first-order increase in aggregate productivity, even taking aggregate capital utilization into account. Thus, if the Durable Goods sector is characterized by a greater tendency to vary its capital use, and receives a disproportionate share of increases in demand during a business cycle upturn, the aggregate economy will experience first-order increases in productivity from this effect.

Another advantage of the capital utilization approach is that it allows the real wage to vary procyclically: $\mathrm{MPL}=\hat{A}+\partial \hat{F} / \partial L$, as before, but now there are first-order effects on $\hat{A}$ and, in addition, $\partial F / \partial L$ may vary procyclically due to changes in the total quantity 
of capital utilization. These effects may be enough to offset the negative effect on $\partial F / \partial L$ that results from diminishing returns to labor.

Finally, note that, just as with markups, it is crucial that the ability to utilize capital differ across sectors. Without this assumption, the marginal product of utilization is equal across sectors in steady state, and all first-order effects on productivity from variations in utilization disappear (assuming that we correct for the effects of changes in total, aggregate capital use).

\section{Simulations}

To demonstrate the quantitative significance of sectoral reallocation and variable capital utilization, and the unimportance of second-order effects, in the DSGE framework above, I undertake a series of simulations. Four model economies will be considered: the baseline one-sector model (I), the basic multi-sector model (II), a one-sector model with capital utilization (III), and the multi-sector model with capital utilization (IV). Note that the first three models can all be written as special cases of model IV. The four-way comparison allows us to study both the variable capital utilization and the sectoral reallocation features of the models independently.

All macroeconomic parameters will be identical across models and held constant throughout the simulations. They are listed in Table I of Figure 1. The values for $\alpha$, $\delta$, and $\gamma_{X}$ are standard, corresponding to labor's share of output, the annual depreciation rate of capital, and the average annual growth rate of TFP in the postwar period. The parameter $\beta$ is chosen so as to be consistent with a $3 \%$ after-tax real interest rate, and $G / Y$ corresponds to the steady-state share of government purchases in the economy. After experimentation with the choice of utility kernel, it was found that the results were essentially invariant to changes in functional form so long as the steady-state Frisch elasticity of labor supply was held constant. ${ }^{16}$ For these simulations, I have thus set

$$
v\left(1-L_{t}\right) \equiv \log C_{t}+\zeta \log \left(1-L_{t}\right)
$$

which is standard in the literature (hence $\sigma=1$ and $\nu=1$ ). The parameter $\zeta$ was chosen to yield a steady-state Frisch labor supply elasticity of about 1.7, which is less

\footnotetext{
${ }^{16}$ The DSGE literature often refers to this quantity as the "compensated elasticity of labor supply." Strictly speaking, as MaCurdy (1981) points out, this is incorrect.
} 
TABle I:

Macroeconomic Parameters: All Models

\begin{aligned} \hline$\alpha & =.65 & \sigma & =1 \\ \delta & =.1 & \nu & =1 \\ \beta & =.985 & \zeta & =1.6 \\ \gamma_{X} & =1.016 & \tau, \mathrm{G} / \mathrm{Y} & =.2\end{aligned}$
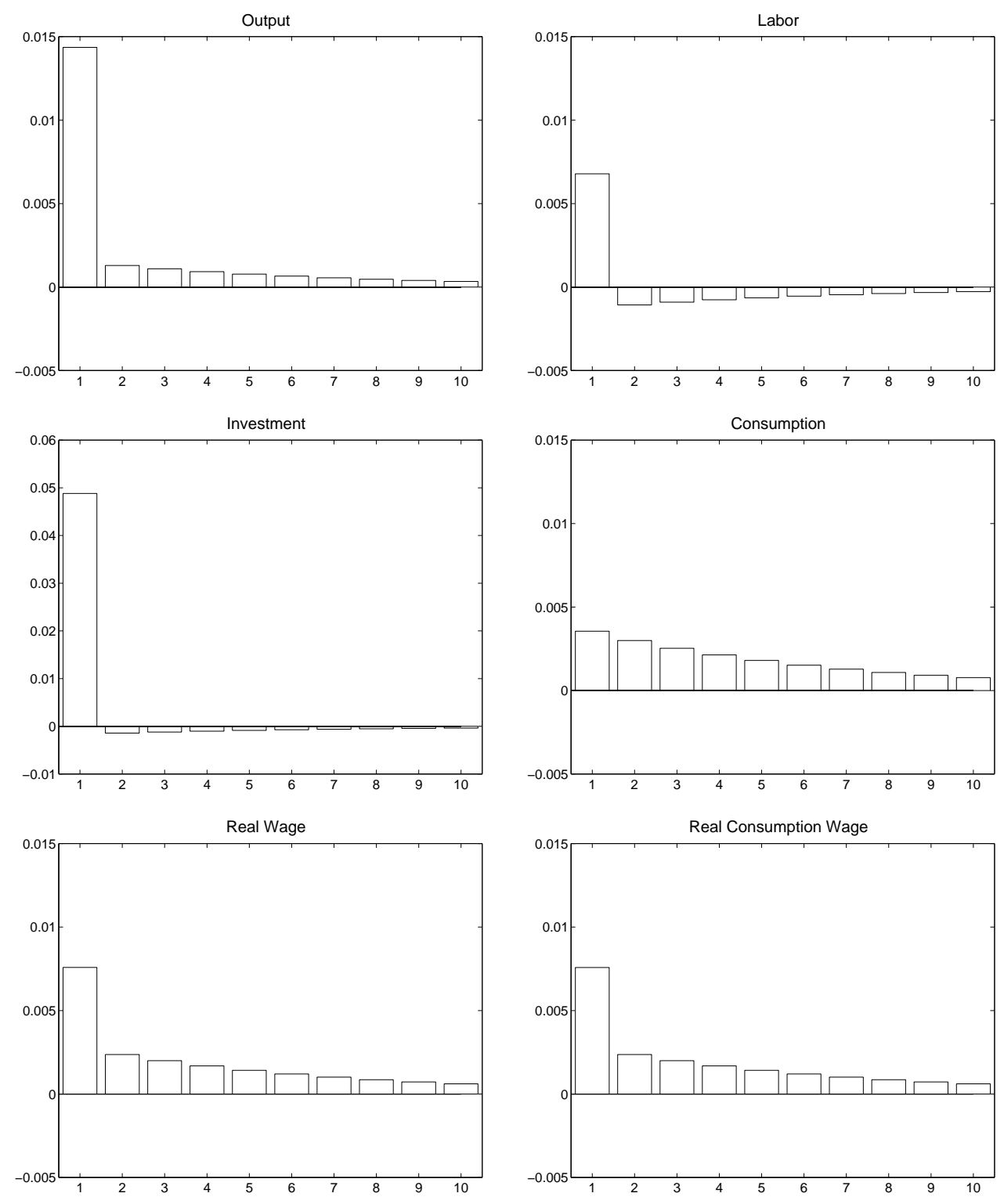

Figure 1: Baseline Model Response to 1\% Technology Shock 
than values chosen by most traditional RBC studies. ${ }^{17}$ A larger Frisch elasticity generates larger responses to economic shocks in equilibrium models, since agents are more willing to substitute leisure across time.

As a calibration exercise, the response of baseline model I to a $1 \%$ technology shockan unforeseen, temporary $1 \%$ exogenous increase in the level of $A_{t}$-is also reported in Figure 1. Consumption, labor, output, and investment all react positively to the shock, consumption by about one third the size of the shock, labor by about two thirds, output by one and a half times, and investment by about five times the size of the shock. These results are very similar to those of King, Plosser, and Rebelo (1988), whose model served as the basis for model I here.

Additional persistence can be introduced into the responses of the model by incorporating adjustment costs, greater lags to adjustment, or exogenous serial correlation in the driving shock. The effects of these additions on the responses of the model are straightforward and are generally avoided in the simulations below. This allows for a clearer isolation of the effects of sectoral reallocation and capital utilization on the standard DSGE framework. $^{18}$

\subsection{Simulation 1: Pure Sectoral Shift}

The importance of linking sectoral reallocation and capital utilization can be demonstrated by considering a pure reallocation of demand across the two sectors of a simple, two-sector economy. For clarity, assume that the two sectors are equal in size and identical in all respects except for their marginal product of capital utilization parameters $\omega_{i}$. The details of the parameterization of the model are given in Table 1 of Figure 2. The absence of a time subscript on a variable indicates its steady-state value. For a pure reallocative shock, I consider a shift in the tastes of consumers away from one sector's good and toward the other's. ${ }^{19}$ The size of this shift is taken to yield a permanent $3 \%$ increase in the share of

\footnotetext{
${ }^{17}$ For the utility kernel $\log C_{t}+\zeta \log \left(1-L_{t}\right)$, it is not difficult to show that the Frisch elasticity of labor supply equals $(1-L) / L$, the steady-state ratio of leisure to labor. Christiano and Eichenbaum (1992) and their followers have typically chosen values in the range of 3-5; Prescott (1986) and his followers have tended to choose values closer to 2 , but typically magnify this elasticity by allowing past values of leisure to enter into the utility function.

18 Also note that although the simulations below involve only a small number of sectors for clarity and calibration purposes, the model itself, and the solution algorithm it uses, are not limited in this respect. Models with a dozen or more sectors are not a computational problem.

19 This is represented in the models as a shock to the taste parameters $\eta_{i}$.
} 
TABLE 1:

Micro Parameters:

Models II \& IV

$A_{i}=[1,1]$

$\alpha_{i}=[.65, .65]$

$\omega_{i}=[.2,1]$

$\phi_{i}=[1.6,1.6]$

$\theta=0.5$

$p_{i} C_{i} / C=[.5, .5]$

$p_{i} I_{i} / I=[.5, .5]$

$p_{i} G_{i} / G=[.5, .5]$

TABLE 2:

Aggregate Effects of $\Delta\left(p_{i} C_{i} / C\right)=[.03,-.03]$ :

Model II

Model IV

\begin{tabular}{crr}
\hline$\hat{A}$ & -.0001 & -.0035 \\
$\hat{U}$ & $N / A$ & -.0043 \\
$\hat{P}_{\mathrm{C}}$ & .0005 & .0002 \\
$\hat{P}_{\mathrm{K}}$ & -.0003 & -.0002
\end{tabular}

$p_{i t} / p_{i}$

$[1.015, .984]$

$[1.008, .992]$

$l_{i t} / l_{i}$

$[1.045, .956]$

$[1.035, .957]$

$u_{i t} / u_{i}$

$N / A$

$[1.020, .971]$
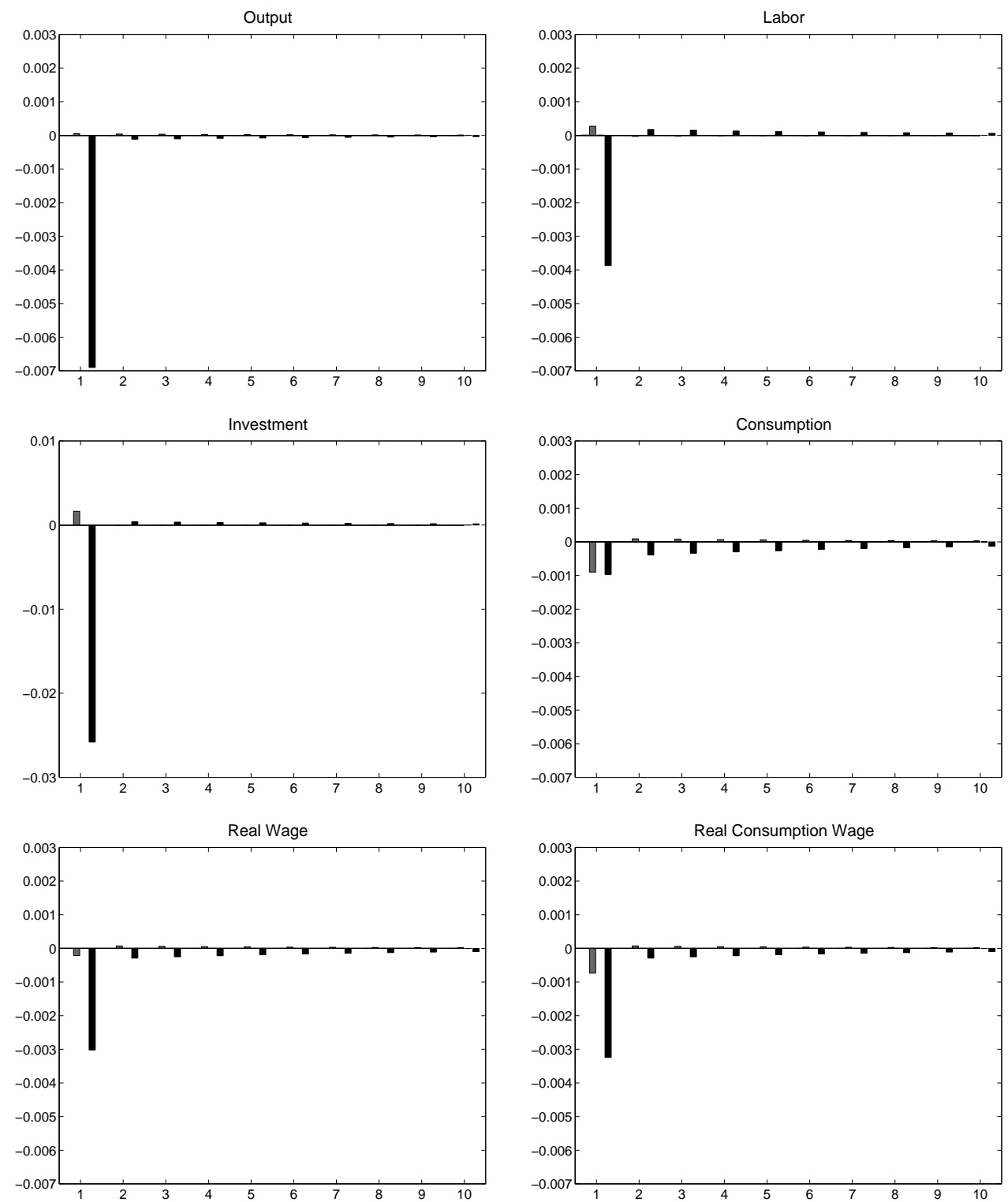

Figure 2: Response of Models II and IV to Pure Sectoral Shift 
total consumption accounted for by the first good, and a corresponding $3 \%$ decrease in the share accounted for by the second good. The impulse responses of the four models are presented in Figure 2, with the four bars for each period (year) representing the impulse responses of each of the four models, reading from left to right.

Obviously, models I and III will yield no response to such a shock, since within their framework all consumption is identical, and the aggregate specification of preferences in (I-1) and (III-1) is unaffected. In sectoral models II and IV, however, the shock clearly will have an effect, and the importance of capital utilization in these effects is apparent in the Figure - the impulse responses of model IV to the taste shift are dramatically larger than those of model II. ${ }^{20}$

Some of the reasons for the larger aggregate responses of model IV can be found in Table II of the Figure. The availability of capital utilization in the model allows for a change in aggregate utilization (defined as $\left.U_{t} \equiv \sum\left(K_{i} / K\right) U_{i t}\right)$ of $-0.43 \%$, which, as in Burnside and Eichenbaum (1996), offsets the effects of diminishing marginal returns to labor and allows for a corresponding magnification of the responses of the model. One manifestation of this is the fall in real wages despite the fall in labor input. In addition, the reallocation of production across sectors yields a change in aggregate productivity of $-0.35 \%$, which also drives down the real wage in the model, and thus provides an additional source of amplification for agents' responses. ${ }^{21}$ The effects of Model II on aggregate productivity are, in contrast, negligible, reflecting their second-order nature, which was demonstrated in section 3.

\footnotetext{
${ }^{20}$ It may be argued that the comparison is somewhat unfair, because reallocative effects in model II as a general rule are larger the more different the sectors between which the reallocation occurs. However, the qualitative result that capital utilization greatly magnifies the effects of sectoral reallocation is robust to variations in the model along these lines.

${ }^{21}$ Note that as in section 3, the measurement of the change in aggregate productivity depends upon our choice of a value for the aggregate parameter $\omega$. Here, and in the simulations that follow, I have taken $\omega \equiv \sum\left(K_{i} / K\right) \omega_{i}$, the weighted average of the value across sectors, with weights corresponding to sector sizes. Alternatively, we could follow Burnside and Eichenbaum (1996), Greenwood, Hercowitz, and Huffman (1988), and others, and simply assign $\omega$ an aggregate value of 1 . This yields an effect on aggregate $\hat{A}$ of $-0.3 \%$. Smaller values of $\omega$ all yield larger (i.e., more negative) estimates of $\hat{A}$, so these choices are fairly conservative. Finally, it should be emphasized that all of the impulse responses in Figure 2 are completely independent of the choice of $\omega$-the choice only affects the decomposition of changes in output (relative to inputs) into components related to the change in aggregate utilization versus the change in aggregate productivity.
} 


\subsection{Simulation 2: Military Purchases Shock}

As a second, more applied example, consider the effects of a shock to military purchases. There are a number of reasons why such a shock is an excellent test of a reallocations-based economic model. First, such shocks are, at least to some extent, observable and widely held to be exogenous. Second, as Ramey and Shapiro (1997) document, shocks to military purchases have been very large in the postwar U.S., and have been highly concentrated in specific sectors of the economy, so that their reallocative effects are potentially very significant. Finally, these shocks are often credited with playing a significant role in postwar U.S. macroeconomic fluctuations, or even used as instruments, yet they are only assigned a minor role in economic fluctuations by standard DSGE models. As is shown below, taking into account their reallocative implications significantly alters this conclusion.

For this simulation, the underlying microeconomic parameters of Models II and IV are presented in Table 1 of Figure 3 (the macroeconomic parameters of all four models are held to be the same as in Simulation 1). The multi-sector models are each divided into two sectors, referred to as the "nonmilitary" and "military" sectors, respectively. All consumption and investment demand is assumed to be for nonmilitary goods, while government purchases are divided between the two sectors in a 2:1 ratio. This corresponds roughly to the state of the U.S. economy in 1988. The hypothetical shock is taken to be a $4 \%$ cut in total government purchases, to be taken entirely out of the military sector in Models II and IV. (For comparison, the defense cutbacks of the early 1990's resulted in a decrease in annual military purchases equal to about $6.9 \%$ of total government purchases, with the transition taking place between 1988 and 1993). As is typical in general equilibrium models, the decrease in purchases is refunded to consumers through a lump-sum rebate.

There is some question as to whether such a shock should be regarded as permanent or temporary. Figure 3 presents the results for a completely temporary, one-year change in the government's purchases of military goods, while Figure 4 presents the response to a shock that is viewed by the agents as persistent, following an $\operatorname{AR}(1)$ process with a coefficient of 0.75 , which corresponds to the coefficient estimated from postwar annual U.S. macroeconomic data. ${ }^{22}$

\footnotetext{
${ }^{22}$ The responses assuming an $\mathrm{AR}(2)$ process for military purchases are very similar.
} 
TABLE 1:

Micro Parameters:

Models II \& IV

$$
\begin{aligned}
A_{i} & =[1,1] \\
\alpha_{i} & =[.65, .65] \\
\omega_{i} & =[.2,1] \\
\phi_{i} & =[1.6,1.6] \\
\theta & =0.5 \\
p_{i} C_{i} / C & =[1,0] \\
p_{i} I_{i} / I & =[1,0] \\
p_{i} G_{i} / G & =[.67, .33]
\end{aligned}
$$
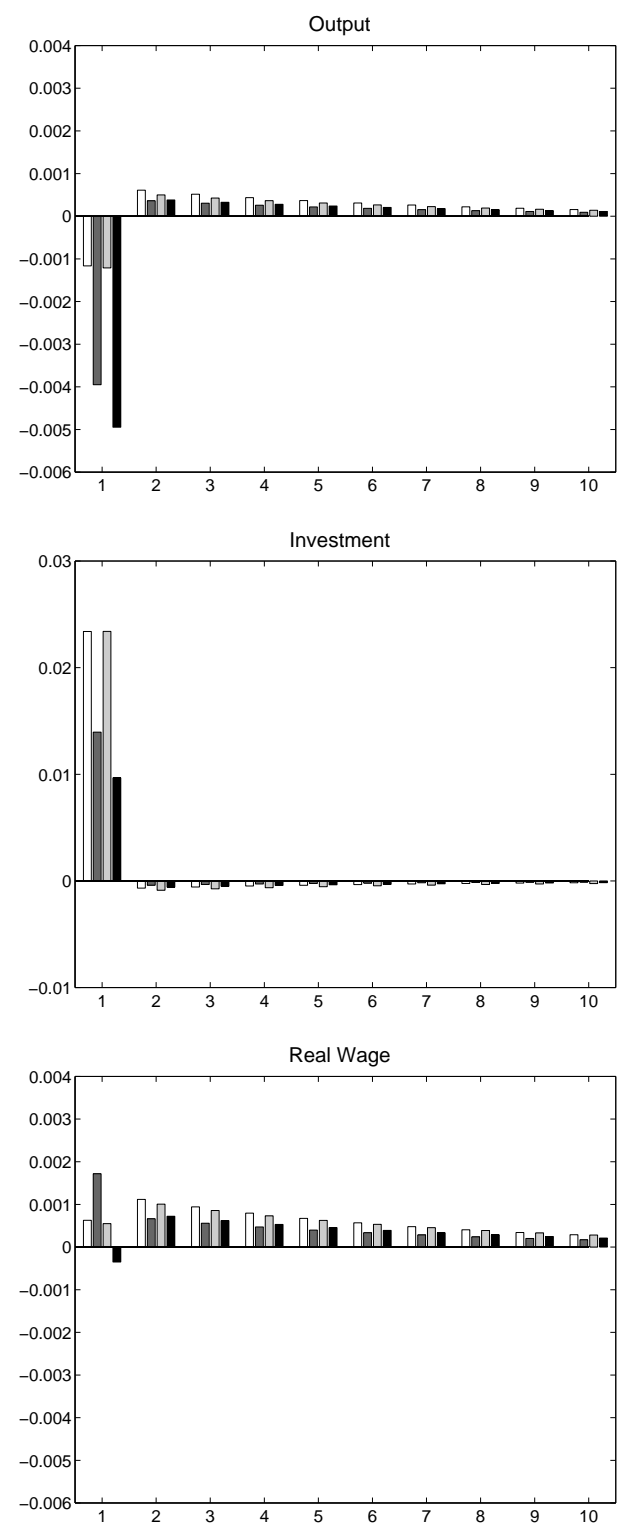

TABLE 2:

Aggregate Effects of $\Delta\left(p_{i} G_{i t} / G\right)=[0,-.04]$ :

Model II Model IV

\begin{tabular}{crr}
\hline$\hat{A}$ & -.0003 & -.0016 \\
$\hat{U}$ & $N / A$ & -.0040 \\
$\hat{P}_{\mathrm{C}}$ & .0041 & .0012 \\
$\hat{P}_{\mathrm{K}}$ & .0041 & .0012
\end{tabular}

$\begin{array}{ccc}p_{i t} / p_{i} & {[1.004, .935]} & {[1.001, .981]} \\ l_{i t} / l_{i} & {[1.007, .822]} & {[1.005, .864]} \\ u_{i t} / u_{i} & N / A & {[1.002, .912]}\end{array}$
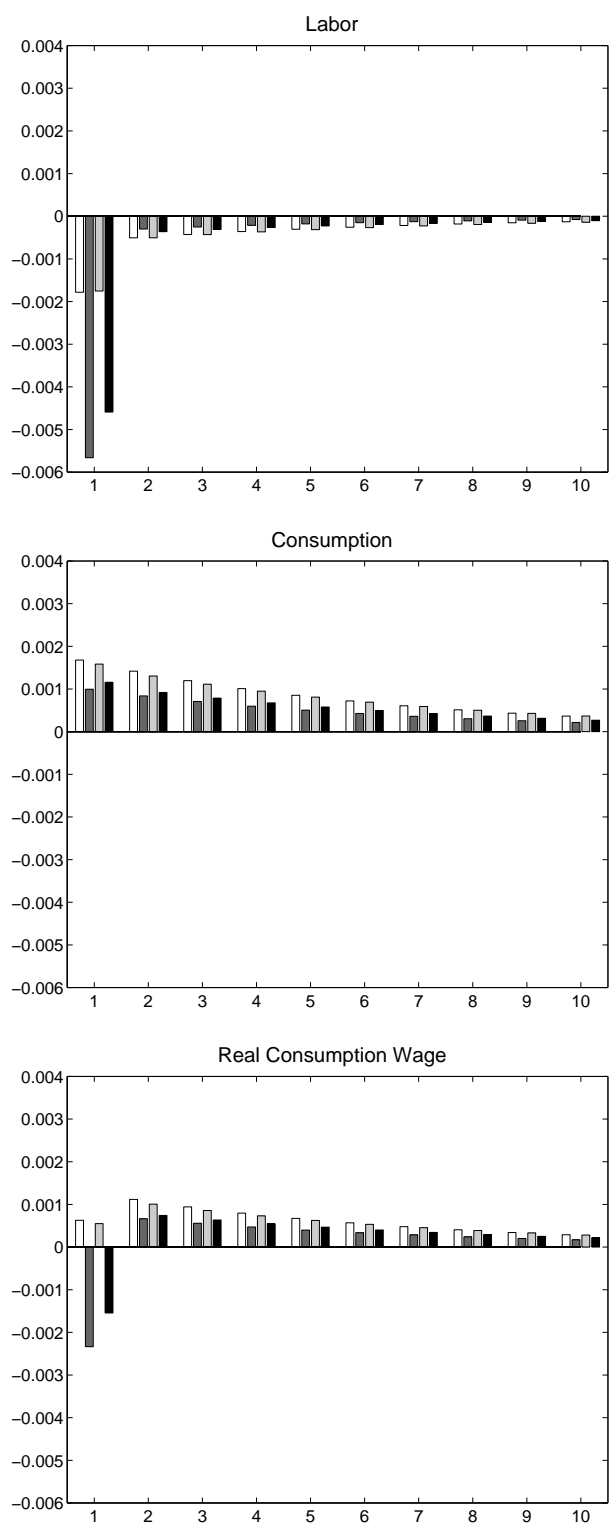

Figure 3: Four Model Responses to Military Purchases Shock 
TABLE 1:

Micro Parameters:

Models II \& IV

$A_{i}=[1,1]$

$\alpha_{i}=[.65, .65]$

$\omega_{i}=[.2,1]$

$\phi_{i}=[1.6,1.6]$

$\theta=0.5$

$p_{i} C_{i} / C=[1,0]$

$p_{i} I_{i} / I=[1,0]$

$p_{i} G_{i} / G=[.67, .33]$

TABLE 2:

Aggregate Effects of $\Delta\left(p_{i} G_{i t} / G\right)=[0,-.04]$ :

Model II

Model IV

\begin{tabular}{ccr}
\hline$\hat{A}$ & -.0003 & -.0016 \\
$\hat{U}$ & $N / A$ & -.0052 \\
$\hat{P}_{\mathrm{C}}$ & .0040 & .0012 \\
$\hat{P}_{\mathrm{K}}$ & .0040 & .0012
\end{tabular}

$\begin{array}{ccc}p_{i t} / p_{i} & {[1.004, .936]} & {[1.001, .982]} \\ l_{i t} / l_{i} & {[1.004, .822]} & {[1.002, .863]} \\ u_{i t} / u_{i} & N / A & {[1.001, .912]}\end{array}$
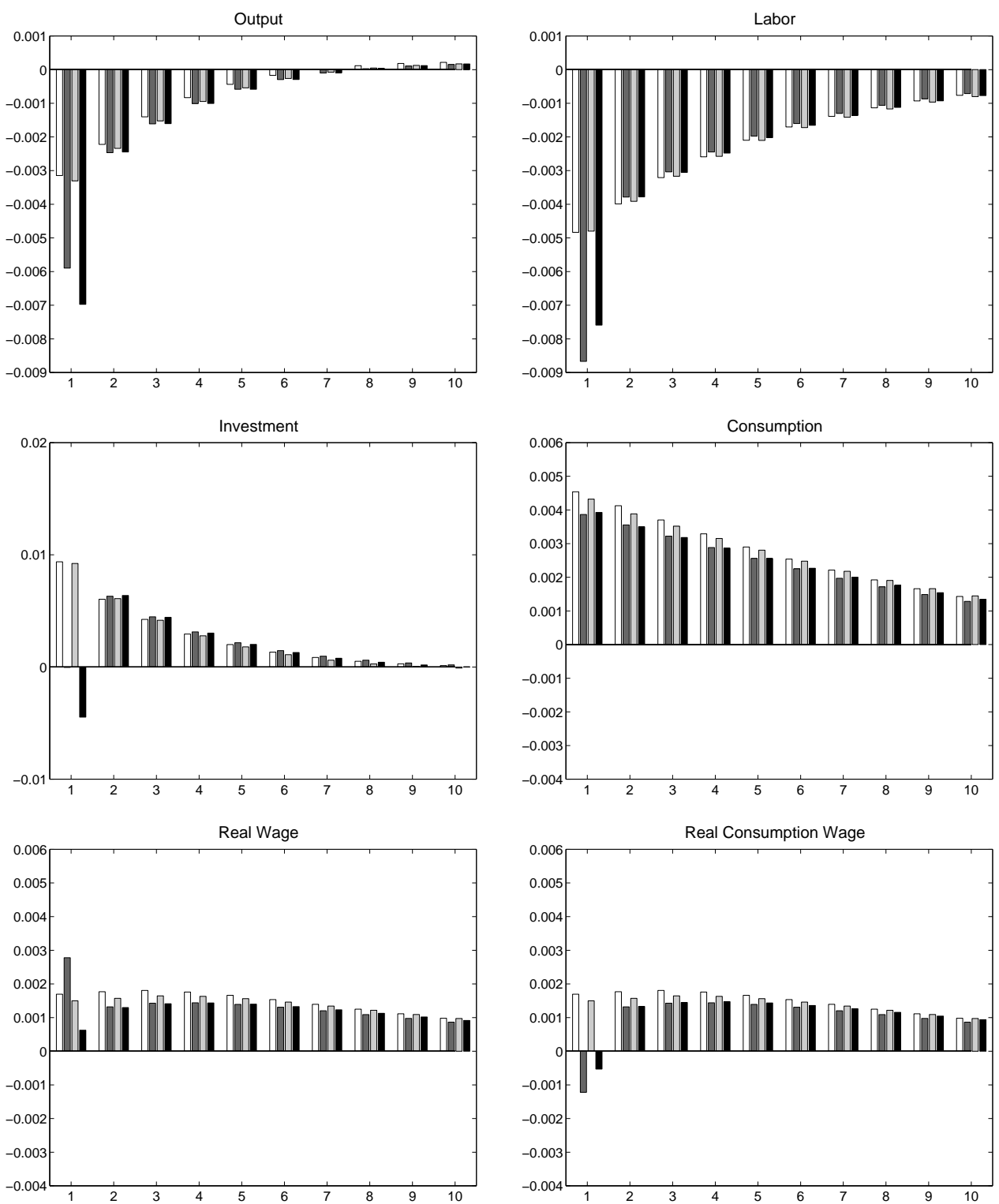

Figure 4: Four Model Responses to Persistent Military Purchases Shock 
Note the large impact on sectoral employment (and to a lesser extent, capital utilization) in the military sector in each of the sectoral models; it is for this reason that a linearization procedure would be suspect immediately following the shock. The nonlinear routine followed here ensures that any second-order effects, to the extent that they are important, will be preserved. In fact, as discussed below, they remain insignificant.

The impulse responses in Figures 3 and 4 demonstrate a number of distinct advantages of the sectoral reallocations-capital utilization framework. First, the sectoral implications of the shock greatly magnify the responses of output and labor input: in Figure 3, the effects are larger by a factor of 4, and in Figure 4, they are larger by a factor of almost 2. Unlike in Ramey and Shapiro (1997), taking into account here the reallocative effects of shocks to government purchases not only allows for a richer set of responses to these shocks, but also clearly demonstrates a much larger role for them in equilibrium models of the business cycle. The results here also demonstrate the importance of these effects for a driving shock that is of a more practical magnitude (less than one-sixth the size of the simulated Korean War buildup that Ramey and Shapiro consider). ${ }^{23}$

The primary reason for the larger responses of output and employment in the sectoral models is a rise in the relative price of consumption (as compared to output). The sectoral effects of the shock lead to a fall in the relative price of military goods, and thus a fall in the price of what agents produce (military plus nonmilitary goods) relative to what they consume (nonmilitary goods only), which in turn leads to a fall in the agents' real consumption wage. As a result, agents' compensation, in terms of their consumption bundles, are substantially less than what they would receive in the standard one-sector model, greatly magnifying their responses to the shock. The greater fall in employment in the reallocations models thus reflects both the deterioration in labor demand in the military sector, and the decrease in agents' labor supply at the new, lower wage in the economy.

This leads to the question of whether there are significant effects on real wages and productivity in the model more generally. Within the context of model IV, and only within that model, the answer is yes. The effect of the misallocation of the capital stock

\footnotetext{
${ }^{23}$ Those authors use as their driving impulse a simulated military buildup that is equal in magnitude to the Korean War - an increase of roughly $25 \%$ in the level of total annual government purchases, all concentrated in the military goods sector.
} 
ex post in Model II is visible as a fall in aggregate productivity $\hat{A}$, but the magnitude of the fall is only $.03 \%$ - a clearly negligible magnitude that again reflects the second-order nature of the effects demonstrated in section 3. In Model IV, the effects are much more substantial, resulting in a $0.16 \%$ drop in aggregate productivity which, together with the fall in aggregate utilization of $0.4 \%$, is enough to drive down the aggregate real product wage (nominal wage divided by a GDP deflator) in Figure 3 despite the fall in labor input. ${ }^{24}$ Thus, a noteworthy feature of the reallocations- and utilization-augmented DSGE model is that it can generate procyclical movements in aggregate productivity and procyclical or acyclical movements in real wages in response to common demand-side shocks. This was evident in the previous simulation (Simulation 1) as well as both of the current ones. One of the principal arguments for exogenous technology shocks as a major driving force for economic fluctuations is thus weakened by the results.

\subsection{Simulation 3: Sectoral Technology Shock}

As a final example, consider the effects of a sectoral technology shock and its reallocative implications. For concreteness, assume that the innovation occurs in an investment-goodsproducing sector. This allows us to demonstrate how the increase in investment demand and reallocation of production to the sector with the technological breakthrough results in a significant shift of resources across sectors and substantially changes the response of the aggregate economy.

The microeconomic parameters of the model are presented in Table 1 of Figure 5. For simplicity, the economy is divided into two sectors, the first consisting of all investment purchases and one third of total government purchases, and the second comprising all consumption and remaining government purchases. This corresponds roughly to the division of the U.S. economy between investment and durable goods and all other goods and services (where "durables consumption" here has been lumped in with investment, as is conventional). The hypothetical shock is taken to be a $3 \%$ increase in the first sector's technology parameter, $A_{1}$, in Models II and IV; given the relative sizes of the sectors in steady state, .32 and .68 (not shown in the Figure), this corresponds to an aggregate pro-

\footnotetext{
${ }^{24}$ Although the real wage in Figure 4 does not decrease, its increase relative to the other models is substantially attenuated by the effects on aggregate productivity and utilization.
} 
TABLE 1:

Micro Parameters:

Models II \& IV

\begin{aligned} \hline$A_{i} & =[1,1] \\ \alpha_{i} & =[.65, .65] \\ \omega_{i} & =[1, .2] \\ \phi_{i} & =[1.6,1.6] \\ \theta & =0.5 \\ p_{i} C_{i} / C & =[0,1] \\ p_{i} I_{i} / I & =[1,0] \\ p_{i} G_{i} / G & =[.33, .67]\end{aligned}$
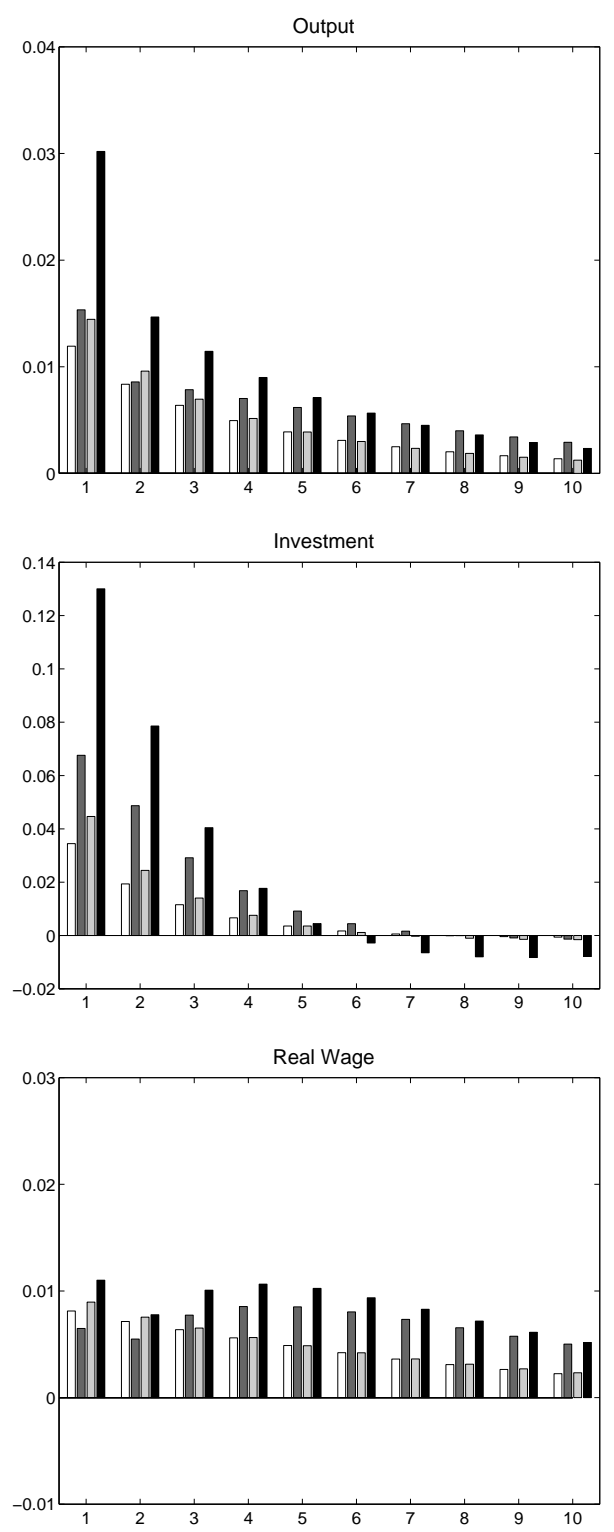

TABLE 2:

Aggregate Effects of $\hat{A}_{i}=[.03,0]$ : Model II Model IV

\begin{tabular}{ccc}
\hline$\hat{A}$ & .0096 & .0134 \\
$\hat{U}$ & $N / A$ & .0271 \\
$\hat{P}_{\mathrm{C}}$ & .0049 & .0068 \\
$\hat{P}_{\mathrm{K}}$ & -.0100 & -.0134 \\
& & \\
$p_{i t} / p_{i}$ & {$[.990,1.005]$} & {$[.987,1.007]$} \\
$l_{i t} / l_{i}$ & {$[1.038, .995]$} & {$[1.083, .990]$} \\
$u_{i t} / u_{i}$ & $N / A$ & {$[1.067,1.009]$}
\end{tabular}
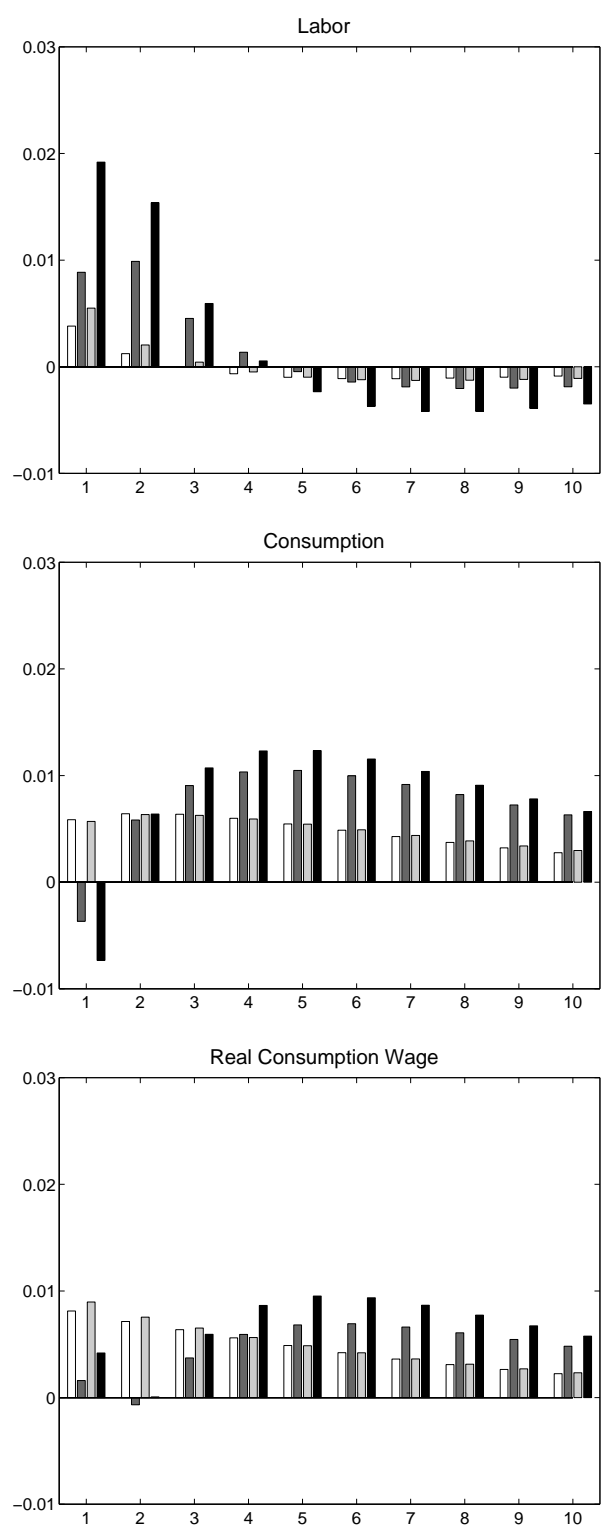

Figure 5: Sectoral Technology Shock 
ductivity shock of $0.96 \%$, or roughly $1 \%$, in the one-sector models (Models I and III). ${ }^{25}$ In both cases, the process guiding the technology term $A_{i t}$ is assumed to be a trend stationary $\operatorname{AR}(1)$ with a persistence coefficient of 0.65 , which corresponds to estimates from annual, aggregate U.S. data. ${ }^{26}$

Figure 5 again shows significant effects on the aggregate variables stemming from the sectoral implications of the shock, particularly when variable capital utilization is also taken into account. The initial output, employment, and investment responses of model IV to the shock are roughly twice as large as those of the other models. Part of the reason for this response is the fall in the relative price of investment in the reallocations models (models II and IV), which encourages agents to work harder and save more than in the standard, one-sector model. However, this is clearly not the only amplifying mechanism, since the response of model II is more muted. The variability of capital utilization in models III and IV plays a role as well: in these models, agents can take additional advantage of the technology shock by increasing capital utilization, which counteracts the diminishing returns to labor and encourages a further increase of output, employment, consumption, and investment. However, neither model II nor model III provides the giant amplification of responses that is characteristic of model IV. The amplification channel unique to that model is the one corresponding to aggregate productivity: the reallocation of production from a sector with low returns to utilization to one with high returns to same yields an additional increase in aggregate productivity of $0.38 \%$, beyond the $0.96 \%$ that was the direct average of the sectoral shocks. (For comparison, the reallocative effect on aggregate productivity in model II is literally 0 .) This is every bit as effective as an exogenous $40 \%$ increase in the size of the shock in the one-sector models, and the agents in Model IV react accordingly. In addition, the relative price effects are larger in the sectoral model with capital utilization, since it allows production to shift sectors without pushing prices back as much toward their original steady-state values. This results in substantially larger effects on the relative prices of investment and consumption, $\hat{P_{K}}$ and $\hat{P_{C}}$, and explains why the effects in Model IV are even greater than $140 \%$ those of Model III (aggregate utilization in Model IV is thus also larger, increasing by about $2.7 \%$, as compared to $0.9 \%$

\footnotetext{
25 The impulse responses of Model I for this simulation would thus be identical to those presented in Figure 1, except for the assumption here that the shock has persistence.

${ }^{26}$ Strictly speaking, $A_{i t}$ in the models follows a stationary AR(1) process without trend, since the trend term was separated out as a deterministic component, $X_{t}$.
} 
in Model III (not shown in the Figure)).

\section{Discussion and Conclusions}

These simulations clearly demonstrate how augmenting the standard DSGE framework to include sectoral heterogeneity and capital utilization can greatly magnify the responses of equilibrium models to exogenous economic shocks, both from the demand side (e.g., government purchases) and from the supply side (e.g., a sectoral technology shock). Although sectoral reallocation and capital utilization can each by themselves act as an amplification and propagation mechanism, the two taken together yield responses that are significantly greater than the sum of their parts. This was evident in all three of the simulations above, and particularly so in Simulations 1 and 3.

The additional effects derive from differences in the marginal product of utilization across sectors. A reallocation from a sector with a low return to utilizing capital to one with a high return to doing so leads to significant, first-order effects on aggregate output relative to aggregate inputs, even after taking changes in aggregate utilization into account. In the simulations presented above, such reallocations led to procyclical real wages and productivity even when the shocks were completely nontechnological in nature (government purchases, shifts in consumer preferences). The model thus offers an explanation for procyclical real wages and productivity that does not depend on large and exogenous shocks to technology. It also matches the empirical findings of Hall (1988) and Evans (1992), who note that aggregate productivity is significantly and positively related to shocks that one would normally consider to be nontechnological in nature (e.g., government purchases).

Moreover, these reallocation-driven increases (or decreases) in aggregate productivity and real wages provide an additional channel through which agents' responses to shocks are amplified. In the third simulation, above, this endogenous aggregate productivity channel effectively increased the size of the technology shock by a full $40 \%$. Thus, much smaller shocks to technology are needed to generate the same effects on aggregate variables that are found in more traditional DSGE studies.

Sectoral models also allow for variation in the relative prices of investment and consumption (as compared to output), which provides another source of amplification for 
agents' responses to a given shock. When the relative price of consumption is higher, agents are induced to consume less; when the relative price of investment is lower, agents are induced to invest more than they would in a one-sector model. These effects are very significant, though somewhat less interesting than the effects on aggregate productivity and real wages described above.

The sectoral model presented here also has the advantage that it is easily generalizable to a large number of sectors, and to a variety of applications. The very close correspondence of the model to traditional one-sector DSGE studies allows for very clean integration of the results with those of other studies (note the ease with which capital utilization was incorporated into the multi-sector framework of section 2). In particular, extensions of the model to include job matching (Merz (1994), Andolfatto (1996)) and Lucas-type "islands" for monetary policy (Cooley and Hansen (1997)) would be tractable and very interesting. Extending the model and ideas of this paper to incorporate an "external" sector, or a source of exogenous external demand for domestic goods and services (which would be exactly analogous to $G$ in the domestic economy as presented here), also would be potentially very rewarding: the equilibrium reallocative implications of fluctuations in external demand could be traced out for a given economy.

Models of sectoral reallocation thus offer many promising avenues for future research, as well as explanations for past empirical findings. It is unlikely that any equilibrium model of the business cycle will be able to match key features of the data without taking into account the reallocative implications of economic shocks. 


\section{Appendix A: Derivations}

This appendix presents the derivation of the multi-sector model economy's aggregate production function and aggregate technology term (9) from section 2. For the general case ( $\alpha_{i}$ unrestricted), we have $Y_{i t} \equiv A_{i t} K_{i t}^{1-\alpha_{i}} L_{i t}^{\alpha_{i}}$, with profit maximization conditions:

$$
\begin{aligned}
L_{i t} & =A_{i t}^{1 /\left(1-\alpha_{i}\right)}\left(\frac{w_{t}}{\alpha_{i} p_{i t}}\right)^{-1 /\left(1-\alpha_{i}\right)} K_{i t} \\
Y_{i t} & =A_{i t}^{1 /\left(1-\alpha_{i}\right)}\left(\frac{w_{t}}{\alpha_{i} p_{i t}}\right)^{-\alpha_{i} /\left(1-\alpha_{i}\right)} K_{i t}
\end{aligned}
$$

The corresponding aggregates are $L_{t} \equiv \sum L_{i t}$ and $Y_{t} \equiv\left(1 / P_{t}\right) \sum p_{i t} Y_{i t}$ (where $P_{t}$ is any valid index of the overall price level), as can be verified by applying Shepard's Lemma to the aggregate profit function (the sum of the sectoral profit functions). We thus have

$$
L_{t} \equiv \psi\left(\frac{w_{t}}{P_{t}}\right) \equiv \sum A_{i t}^{1 /\left(1-\alpha_{i}\right)}\left(\frac{p_{i t}}{P_{t}}\right)^{1 /\left(1-\alpha_{i}\right)}\left(\frac{w_{t}}{P_{t}}\right)^{-1 /\left(1-\alpha_{i}\right)} \alpha_{i}^{1 /\left(1-\alpha_{i}\right)} K_{i t}
$$

which is a continuous, decreasing, surjective function of $\left(w_{t} / P_{t}\right)$ onto the nonnegative real numbers, given all the other parameters. Thus, $\psi$ is invertible, and $w_{t} / P_{t}=\psi^{-1}\left(L_{t}\right)$. Note that we have notationally suppressed the dependence of $\psi$ and $\psi^{-1}$ on the parameters $\alpha_{i}$.

Substituting $\psi^{-1}$ into the equation for $Y_{t}$ yields the aggregate production function for the system:

$$
\begin{aligned}
Y_{t} & =\sum A_{i t}^{1 /\left(1-\alpha_{i}\right)}\left(\frac{p_{i t}}{P_{t}}\right)^{1 /\left(1-\alpha_{i}\right)}\left(\psi^{-1}\left(L_{t}\right)\right)^{-\alpha_{i} /\left(1-\alpha_{i}\right)} \alpha_{i}^{\alpha_{i} /\left(1-\alpha_{i}\right)} K_{i t} \\
& =X_{t}^{1 /(1-\alpha)} K_{t} \sum\left(\frac{A_{i t}}{X_{t}}\right)^{1 /\left(1-\alpha_{i}\right)}\left(\frac{p_{i t}}{P_{t}}\right)^{1 /\left(1-\alpha_{i}\right)}\left(\frac{K_{i t}}{K_{t}}\right) \alpha_{i}^{\alpha_{i} /\left(1-\alpha_{i}\right)}\left(\psi^{-1}\left(L_{t}\right)\right)^{-\alpha_{i} /\left(1-\alpha_{i}\right)}(\mathrm{A} 4)
\end{aligned}
$$

Pulling the quantity $X_{t}$ out of the summation is justified to first order by equation (A6) - see the example after that equation, below. Note that $Y_{t}$ is not a linear function of $K_{t}$ because there are additional terms that come in through $\psi^{-1}$.

As long as the distributional terms $\left(p_{i t} / P_{t}\right),\left(K_{i t} / K_{t}\right)$, and $\left(A_{i t} / X_{t}\right)$ are held fixed in (A4) (and we should rewrite (A3) to make this apparent for $\psi^{-1}$ as well), aggregate output $Y_{t}$ is a stable function of the aggregate inputs $K_{t}$ and $L_{t}$. However, changes in these distributional terms will result in changes to the functional form of (A4), and in general these cannot be captured in terms of a simple mulitplicative technology term $A_{t}$ such as that presented in equation (9) of section 2 .

Such an expression for technology can be obtained, however, when we restrict ourselves to relatively small variations in the $\alpha_{i}$ about some central $\alpha$ and to a neighborhood of the economy's steady state. First, observe that in general we can write $L_{t}$ and $Y_{t}$, with the aid of (A1) and (A2), 
as:

$$
\begin{aligned}
& L_{t}=\left[\sum A_{i t}^{1 /\left(1-\alpha_{i}\right)}\left(\frac{p_{i t}}{P_{t}}\right)^{1 /\left(1-\alpha_{i}\right)}\left(\frac{w_{t}}{P_{t}}\right)^{d \alpha_{i} /(1-\alpha)\left(1-\alpha_{i}\right)} \frac{\alpha_{i}^{\alpha_{i} /\left(1-\alpha_{i}\right)}}{\alpha^{\alpha /(1-\alpha)}} \frac{\alpha_{i}}{\alpha} \frac{K_{i t}}{K_{t}}\right]\left(\frac{w_{t}}{\alpha P_{t}}\right)^{-1 /(1-\alpha)} K_{t} \\
& Y_{t}=\left[\sum A_{i t}^{1 /\left(1-\alpha_{i}\right)}\left(\frac{p_{i t}}{P_{t}}\right)^{1 /\left(1-\alpha_{i}\right)}\left(\frac{w_{t}}{P_{t}}\right)^{d \alpha_{i} /(1-\alpha)\left(1-\alpha_{i}\right)} \frac{\alpha_{i}^{\alpha_{i} /\left(1-\alpha_{i}\right)}}{\alpha^{\alpha /(1-\alpha)}} \frac{K_{i t}}{K_{t}}\right]\left(\frac{w_{t}}{\alpha P_{t}}\right)^{-\alpha /(1-\alpha)} K_{t}
\end{aligned}
$$

where $d \alpha_{i} \equiv \alpha_{i}-\alpha$. Let the bracketed terms be denoted by $A_{L}$ and $A_{Y}$, respectively.

Given the $\alpha_{i}$, we may now choose the constant $\alpha$ so as to satisfy:

$$
\sum d \alpha_{i} A_{i}^{1 /\left(1-\alpha_{i}\right)}\left(\frac{p_{i}}{P}\right)^{1 /\left(1-\alpha_{i}\right)} \frac{K_{i}}{K}=0
$$

where the lack of a time subscript on a variable denotes its steady-state value. This is easily done by setting

$$
\alpha \equiv \sum \alpha_{i} A_{i}^{1 /\left(1-\alpha_{i}\right)}\left(\frac{p_{i}}{P}\right)^{1 /\left(1-\alpha_{i}\right)} \frac{K_{i}}{K} / \sum A_{i}^{1 /\left(1-\alpha_{i}\right)}\left(\frac{p_{i}}{P}\right)^{1 /\left(1-\alpha_{i}\right)} \frac{K_{i}}{K}
$$

(which, to first order, is just $\alpha \equiv \sum w L_{i} / \sum p_{i} Y_{i}$ ). Equation (A5) and the one that follows have been starred to highlight their importance.

For small deviations of the variables $A_{i t}, p_{i t} / P_{t}$, and $K_{i t} / K_{t}$ from their steady-state values, and small variations in the $\alpha_{i}$, we then have

$$
\sum d \alpha_{i} A_{i t}^{1 /\left(1-\alpha_{i}\right)}\left(\frac{p_{i t}}{P_{t}}\right)^{1 /\left(1-\alpha_{i}\right)} \frac{K_{i t}}{K_{t}}=0
$$

to first order. For example, $A_{i t}^{1 /\left(1-\alpha_{i}\right)}=A_{i}^{1 /(1-\alpha)}+$ first-order terms, which become second-order and hence negligible when substituted into (A6).

Making use of (A6) to simplify $A_{L}$ and $A_{Y}$ reveals that these two quantities both equal

$$
\left[\sum A_{i t}^{1 /\left(1-\alpha_{i}\right)}\left(\frac{p_{i t}}{P_{t}}\right)^{1 /\left(1-\alpha_{i}\right)} \frac{K_{i t}}{K_{t}}\right]
$$

to first order. For example,

$$
\begin{aligned}
A_{Y} & =\sum A_{i t}^{1 /\left(1-\alpha_{i}\right)}\left(\frac{p_{i t}}{P_{t}}\right)^{1 /\left(1-\alpha_{i}\right)}\left(\frac{w_{t}}{P_{t}}\right)^{d \alpha_{i} /(1-\alpha)\left(1-\alpha_{i}\right)} \frac{\alpha_{i}^{\alpha_{i} /\left(1-\alpha_{i}\right)}}{\alpha^{\alpha /(1-\alpha)}} \frac{K_{i t}}{K_{t}} \\
& =\sum A_{i t}^{1 /\left(1-\alpha_{i}\right)}\left(\frac{p_{i t}}{P_{t}}\right)^{1 /\left(1-\alpha_{i}\right)}\left(1-\log \left(\frac{w_{t}}{P_{t}}\right) \frac{d \alpha_{i}}{(1-\alpha)^{2}}\right) \times \\
& =\sum A_{i t}^{1 /\left(1-\alpha_{i}\right)}\left(\frac{p_{i t}}{P_{t}}\right)^{1 /\left(1-\alpha_{i}\right)} \frac{K_{i t}}{K_{t}} \quad \text { after applying (A6). }
\end{aligned}
$$


An analogous calculation can be performed for $A_{L}$. We thus have:

$$
\begin{aligned}
& L_{t}=A_{t}^{1 /(1-\alpha)}\left(\frac{w_{t}}{\alpha P_{t}}\right)^{-1 /(1-\alpha)} K_{t} \\
& Y_{t}=A_{t}^{1 /(1-\alpha)}\left(\frac{w_{t}}{\alpha P_{t}}\right)^{-\alpha /(1-\alpha)} K_{t}
\end{aligned}
$$

where

$$
A_{t} \equiv\left[\sum A_{i t}^{1 /\left(1-\alpha_{i}\right)}\left(\frac{p_{i t}}{P_{t}}\right)^{1 /\left(1-\alpha_{i}\right)} \frac{K_{i t}}{K_{t}}\right]^{1-\alpha}
$$

and where the equalities all hold in a neighborhood of the steady state and for small variations in the $\alpha_{i}$. In general, (A9) cannot be simplified any further.

Together, (A7) and (A8) imply

$$
Y_{t}=A_{t} K_{t}^{1-\alpha} L_{t}^{\alpha}
$$

which completes the separation of (A4) into aggregate quantities and a multiplicatively separable distributional or technology term, $A_{t}$. 


\section{Appendix B: Solution Method}

The numerical solution method for the models and their dynamic impulse responses follows closely the log-linearization procedure of King, Plosser, and Rebelo (1987). To solve the baseline onesector model, these authors take the representative agent's system of optimality conditions and derive their log-linear approximations in a neighborhood of the model's deterministic steady state. For small perturbations, the solution of this system yields a good approximation to the true solution of the model, even in a stochastic setting. ${ }^{27}$ See King, Plosser, and Rebelo (1987) for the details of the method.

As was mentioned in the text, however, a linearization procedure is suspect when applied to shocks at the sectoral level. Only when these shocks have had a chance to die down is a linearization appropriate. Given the structure of adjustment costs or adjustment lags in the model and a candidate shock, it is typically possible to determine a set number of periods $k$ after which a linearization procedure produces a good approximation to the equations of the model. The system's equations for periods $k$ and beyond can then be linearized exactly as in the King, Plosser, and Rebelo framework. Taking $k=0$ thus corresponds exactly to the KPR procedure. Taking $k=1$, we would guess hypothetical values for all the time $t$ variables of the system, require that they satisfy all the time $t$ constraints of the model nonlinearly, trace out the implied values of time $t+1$ state variables that result, and then solve the model linearly from period $t+1$ forward, given these "initial" time $t+1$ state variables. The accuracy of the initial guess is determined by the optimality conditions for the costate variables that must be satisfied on the boundary between periods $t$ and $t+1$; if these conditions are not satisfied, another guess is made and the solution procedure reiterated. Solving the model for $k=2$ is then simply a matter of adding another period's worth of guessed variables and another period's worth of costate restrictions, and so on for $k \geq 3$.

In practice, the special structure of the models of the text allows us to take $k=1$. This is because the assumption that capital is freely mobile one period after the realization of the shock implies that the large movements in sectoral output, utilization, employment, and prices that result from the short-run fixity of capital will largely be eliminated by the beginning of period $t+1$. Longer lags to capital adjustment could easily be incorporated by extending this

${ }^{27}$ Validity in the stochastic setting can be seen by recognizing that

$$
\begin{aligned}
E[X Y] & =E[X] E[Y]+\operatorname{Cov}(X, Y) \\
& \approx E[X] E[Y]
\end{aligned}
$$

is an excellent approximation when $\operatorname{Cov}(X, Y)$ is small relative to $E[X] E[Y]$. This is the case for all of the macroeconomic variables of the system $\left(A_{t}, Y_{t},\left(1+r_{t}\right)\right.$, etc.). All the stochastic equations of the system (involving cross-terms such as $E[X Y]$ ) can thus be replaced by their certainty equivalents (involving $E[X] E[Y])$, and these certainty equivalents are identical to the equations for the deterministic case. 
boundary forward a few periods, but wouldn't materially alter the solution algorithm or impact the demonstrated importance of effects of sectoral reallocation in the models.

Thus, the solution algorithm for the simulations in the text proceeds as follows: hypothesize values for the wage $w_{t}$ and relative prices $p_{i t}$ for period $t$. Given these quantities, all other time $t$ variables of the system can be determined. This then implies a value for the time $(t+1)$ capital stock $K_{t+1}$. The time $(t+1)$ distribution of capital across sectors is easily determined by a zeroprofit condition, since capital is freely mobile at the end of period $t$. Given $K_{t+1}$, the log-linear approximate solution for all time $(t+1)$ (and beyond) variables can quickly be obtained using the KPR linearization procedure. If the time $(t+1)$ and time $t$ values for consumption and labor satisfy the consumer's Euler equation, then we have an equilibrium; otherwise, we guess new values for $w_{t}$ and $p_{i t}$, and reiterate the procedure.

For this algorithm, convergence of the nonlinear routines was never a problem, and solutions were typically found very quickly, within a few iterations, even for models with a large number of sectors. Detailed notes about the procedures and Matlab routines are available from the author upon request. 
Abraham, Katherine And Lawrence Katz. "Cyclical Unemployment: Sectoral Shifts or Aggregate Disturbances?" J. P. E. 94 (1986), pp. 507-522.

Andolfatto, David. "Business Cycles and Labor Market Search," A. E. R. 86 (1996), pp. 11232.

Baily, Martin, Charles Hulten, and David Campbell, "Productivity Dynamics in Manufacturing Plants," Brookings Papers on Economic Activity (1992), pp. 187-249

Basu, Susanto. "Procyclical Productivity: Increasing Returns or Cyclical Utilization?" Q. J. E. 109 (1996), pp. 719-51.

Basu, Susanto And John Fernald. "Returns to Scale in U.S. Production: Estimates and Implications," J. P. E. 105 (1997a), pp. 249-83.

Basu, Susanto and John Fernald. "Aggregate Technology and Aggregate Productivity," Federal Reserve International Finance Discussion Paper 593 (1997b).

Basu, Susanto, John Fernald, and Michael Horvath. "Aggregate Production Function Failures and Business Cycle Analysis," mimeo (1997).

Burnside, Craig and Martin Eichenbaum. "Factor-Hoarding and the Propagation of Business Cycle Shocks," A. E. R. 86 (1996), pp. 1154-74.

Burnside, Craig, Martin Eichenbaum, and Sergio Rebelo. "Capital Utilizaton and Returns to Scale," NBER Working Paper 5125 (1995).

Burnside, Craig, Martin Eichenbaum, and Sergio Rebelo. "Sectoral Solow Residuals," European Economic Review 40 (1996), pp. 861-9.

Campbell, Jeffrey and Kenneth Kuttner. "Macroeconomic Effects of Employment Reallocation," Carnegie-Rochester Conference Series on Public Policy 44 (1996), pp. 87-116.

Christiano, Lawrence and Martin Eichenbaum. "Current Real-Business-Cycle Theories and Aggregate Labor-Market Fluctuations," A. E. R. 82 (1992), pp. 430-50.

Cooley, Thomas and Gary Hansen. "Unanticipated Money Growth and the Business Cycle Reconsidered," J. Money, Credit, and Banking 29 (1997), pp. 624-48.

Davis, Steven. "Fluctuations in the Pace of Labor Reallocation," Carnegie-Rochester Conference Series on Public Policy 21 (1987), pp. 335-402.

Davis, Steven and John Haltiwanger. "Gross Job Creation and Destruction: Microeconomic Evidence and Macroeconomic Implications," NBER Macroeconomics Annual V (1990), pp. 123-68.

Davis, Steven and John Haltiwanger. "Gross Job Creation, Gross Job Destruction, and Employment Reallocation," Q. J. E. 107 (1992), pp. 819-63.

Davis, Steven, John Haltiwanger, And Scott Schuh. Job Creationn and Destruction (Cambridge, MA: MIT Press, 1996).

Evans, Charles. "Productivity Shocks and Real Business Cycles," J. Monetary Econ. 29 (1992), pp. 191-208.

Galí, Jordi. "Monopolistic Competition, Business Cycles, and the Composition of Aggregate Demand," J. Econ. Theory 63 (1994), pp. 73-96. 
Greenwood, Jeremy, Zvi Hercowitz, and Gregory Huffman. "Investment, Capacity Utilization, and the Real Business Cycle," A. E. R. 78 (1988), pp. 402-17.

Griliches, Zvi And V. Ringstad. Economies of Scale and the Form of the Production Function: An Econometric Study of Norwegian Manufacturing Establishment Data (North-Holland: Amsterdam, 1971).

Hall, Robert. "The Role of Consumption in Economic Fluctuations," in The American Business Cycle, ed. Robert Gordon (1986), pp. 237-55.

Hall, Robert. "The Relation between Price and Marginal Cost in U.S. Industry," J. P. E. 96 (1988), pp. 921-47.

Hamilton, James. "A Neoclassical Model of Unemployment and the Business Cycle," J. P. E. 96 (1988), pp. 593-617.

Horvath, Michael. "Cyclicality and Sectoral Linkages: Aggregate Fluctuations from Independent Sectoral Shocks," mimeo (1997a).

Horvath, Michael. "Sectoral Shocks and Aggregate Fluctuations," mimeo (1997b).

King, Robert, Charles Plosser and Sergio Rebelo. "Production, Growth, and Business Cycles," J. Monetary Econ. 21 (1988), pp. 195-232 and unpublished Technical Appendix, mimeo (1987).

Kydland, Finn And Edward Prescott. "Time to Build and Aggregate Fluctuations," Econometrica 50 (1982), pp. 1345-70.

LiLIEN, DAVID. "Sectoral Shifts and Cyclical Unemployment," J. P. E. 90 (1982), pp. 777-793.

Long, John and Charles Plosser. "Real Business Cycles," J. P. E. 91 (1983), pp. 39-69.

MaCurdy, Thomas. “An Empirical Model of Labor Supply in a Life-Cycle Setting,” J. P. E. 89 (1981), pp. 1059-85.

Merz, Monika. "Heterogeneous Job Matches and the Cyclical Behavior of Labor Turnover," mimeo (1994).

Phelan, Christopher and Alberto Trejos. "Optimal Sectoral Shifts," mimeo (1995).

RAmey, Valerie And Matthew Shapiro. "Costly Capital Reallocation and the Effects of Government Spending," mimeo (1997).

Ricardo, David. On the Principles of Political Economy and Taxation (Cambridge: Cambridge University Press, 1954).

Rogerson, Richard. "An Equilibrium Model of Sectoral Reallocation," J. P. E. 95 (1987), pp. 824-34.

Rotemberg, Julio and Michael Woodford. "Oligopolistic Pricing and the Effects of Aggregate Demand on Economic Activity," J. P. E. 100 (1992), pp. 1153-1207.

Shapiro, Matthew. "Macroeconomic Implications of Variation in the Workweek of Capital," Brookings Papers on Economic Activity (1996), pp. 79-133.

Shleifer, Andrei. "Implementation Cycles," J. P. E. 94 (1986), pp. 1163-90.

Solow, RoBert. "Technical Change and the Aggregate Production Function," Rev. Econ. and Stat. 39 (1957), pp. 312-20. 